\title{
TRPV1 expressed throughout the arterial circulation enables inflammatory vasoconstriction
}

Thieu X. Phan ${ }^{1,2}$, Hoai T. Ton ${ }^{1,2}$, Hajnalka Gulyás ${ }^{3}$, Róbert Pórszász ${ }^{3}$, Attila Tóth ${ }^{4}$, Rebekah Russo $^{5}$, Matthew W. Kay ${ }^{5}$, Niaz Sahibzada ${ }^{1}$ and Gerard P. Ahern ${ }^{*}$

${ }^{1}$ Department of Pharmacology and Physiology, Georgetown University, Washington DC, USA

${ }^{2}$ Department of Biology, Vinh University, Vinh City, Nghe An, Vietnam

${ }^{3}$ Department of Pharmacology and Pharmacotherapy, Faculty of Medicine, University of Debrecen, Doctoral School of Pharmaceutical Sciences, Debrecen, Hungary

${ }^{4}$ Division of Clinical Physiology, Institute of Cardiology, Faculty of Medicine, University of Debrecen, Debrecen, Hungary

${ }^{5}$ Department of Biomedical Engineering, George Washington University, Washington DC, USA

Address correspondence to:

Gerard Ahern, Department of Pharmacology and Physiology, Georgetown University, Med-Dent Building SW401, 3900 Reservoir Rd Washington DC 20007,USA, Phone (202) 687 9678; Fax (202) 687 2585; Email:gpa3@georgetown.edu

Total word count: 8193

Subject Areas: Ion Channels/Membrane Transport, Vascular biology 


\begin{abstract}
The capsaicin receptor, TRPV1, is a key ion channel involved in inflammatory pain signaling. Although mainly studied in sensory nerves, there are reports of TRPV1 expression in isolated segments of the vasculature, but whether the channel localizes to vascular endothelium or smooth muscle is controversial and the distribution and functional roles of TRPV1 in arteries remain unknown. We mapped functional TRPV1 expression throughout the mouse arterial circulation. Analysis of reporter mouse lines TRPV1 ${ }^{\text {PLAP-nlacZ }}$ and TRPV1-Cre:tdTomato combined with $\mathrm{Ca}^{2+}$ imaging revealed specific localization of TRPV1 to smooth muscle of terminal arterioles in the heart, fat and skeletal muscle. Capsaicin evoked inward currents and raised intracellular $\mathrm{Ca}^{2+}$ levels in arterial smooth muscle cells, constricted arterioles ex vivo and in vivo and increased systemic blood pressure in mice and rats. Further, capsaicin markedly and dose-dependently reduced coronary flow. Pharmacologic and/or genetic disruption of TRPV1 abolished all these effects of capsaicin as well as vasoconstriction triggered by lysophosphatidic acid, a bioactive lipid generated by platelets and atherogenic plaques. Notably, ablation of sensory nerves did not affect the responses to capsaicin revealing a vascular smooth musclerestricted signaling mechanism. Moreover, unlike in sensory nerves, TRPV1 function in arteries was resistant to activity-induced desensitization. Thus, TRPV1 activation in vascular myocytes of resistance arterioles enables a persistent depolarizing current, leading to constriction of coronary, skeletal muscle, and adipose arterioles and a sustained increase in systemic blood pressure.
\end{abstract}

Keywords: TRPV1, vascular smooth muscle, blood pressure, capsaicin, lysophosphatidic aci 


\section{Introduction}

Transient Receptor Potential Vanilloid 1 (TRPV1) is perhaps the best-studied member of the TRP ion channel family. The existence of highly specific and potent pharmacological agonists, including capsaicin and resiniferatoxin, ${ }^{1,2}$ and spider toxins, ${ }^{3}$ has enabled the interrogation of TRPV1 from the molecular to the whole animal level. Furthermore, pioneering high-resolution ( 3.4 Angstroms) electron cryomicroscopy has revealed key structural features of the TRPV1 channel in the un-liganded and bound state. ${ }^{4-6}$ The functional roles of TRPV1 have been appreciated for over 100 years owing to the ability of capsaicin to elicit pronounced pain responses. ${ }^{1,2}$ TRPV1 is highly expressed in a subset of sensory afferent nerves with cell bodies located in the dorsal root, trigeminal and nodose/jugular ganglia. ${ }^{7}$ In many of these neurons TRPV1 acts as an integrator of noxious thermal and chemical stimuli including elevated heat, protons, and lipid mediators. ${ }^{2,8}$ These stimuli activate TRPV1, a non-selective cation channel with considerable $\mathrm{Ca}^{2+}$ permeability, ${ }^{7}$ to depolarize the membrane and also to trigger the secretion of neuropeptides from nerve endings. ${ }^{1,2}$ Accordingly, genetic or pharmacologic inhibition of TRPV1 attenuates inflammatory pain. ${ }^{9-11}$ Further, recent studies have revealed additional functions for TRPV1 as a transduction channel in both itch- and warm-temperature coding neurons, ${ }^{12,13}$ thus indicating a broader role in somatosensory transmission.

Outside of sensory nerves the expression and function of TRPV1 remains controversial. While there is considerable evidence for expression in select brain neurons, ${ }^{14}$ whether or not TRPV1 is functionally present in other tissues is less clear. Of note, several studies have described TRPV1 function in arterial smooth muscle cells, ${ }^{14-16}$ confirmed by measuring $\mathrm{Ca}^{2+}$ transients or vasoconstriction in response to capsaicin. On the other hand, other studies have located TRPV1 
in vascular endothelium, ${ }^{17,18}$ and indicated that TRPV1 agonists dilate vessels to lower blood pressure. To further complicate matters, TRPV1 in sensory nerves can exert a neurogenic regulation of nearby blood vessels through the release of vasoactive peptides such as calcitonin gene related peptide (CGRP) or substance P. Indeed, local application of capsaicin to the skin is well known to cause a vasodilation response accompanied by edema. ${ }^{19,20}$

Here we have exploited reporter mice combined with functional analyses to map TRPV1 expression throughout the arterial circulation. We show that TRPV1 is restricted to the smooth muscle of arterioles, notably in skeletal muscle, heart and adipose tissues. TRPV1 agonists, including inflammatory lipid mediators, evoke membrane currents in isolated vascular myocytes to persistently constrict arteries, decrease coronary flow and increase blood pressure. Furthermore, these effects are retained after ablation of sensory nerves indicating an arteriolemediated signaling mechanism. These data reveal a fundamental mechanism for transducing inflammatory stimuli into arterial constriction. 


\section{Methods}

Animals: All experimental procedures involving mice and rats were approved by the Georgetown University and George Washington University Animal Care and Use Committee and the Ethics Committee on Animal Research of the University of Debrecen. Both Wistar and Sprague- rats (250-450 g) and C57B1 mice (25-30 g) were housed at 24-25 ${ }^{\circ} \mathrm{C}$ and had ad libitum access to a standard laboratory chow and water.

Mouse lines: The TRPV1-Cre transgenic mouse line (donated by Dr. Mark Hoon, NIH) was created using a BAC transgene containing the entire TRPV1 gene/promoter (50 kbp of upstream DNA) and IRES-Cre-recombinase. ${ }^{21}$ Importantly, Cre expression in this mouse faithfully corresponds with the expression of endogenous TRPV1. The TRPV1-Cre (hemizygous) mice were crossed with ai9 ROSA-stop- tdTomato mice (The Jackson Laboratory). The TRPV1 ${ }^{\text {PLAP- }}$ ${ }^{\text {nlacZ }}$ mice (Jackson Laboratory) were developed by Allan Bausbaum and colleagues (UCSF) to express human placental alkaline phosphatase (PLAP) and nuclear lacZ under the control of the TRPV1 promoter. $^{14}$ The targeting construct contains an IRES-PLAP-IRES-nlacZ cassette immediately 3' of the TRPV1 stop codon, which permits the transcription and translation of PLAP and nlacZ in cells expressing TRPV1 without disrupting the TRPV1 coding region. TRPV1-null mice were purchased from The Jackson Laboratory. TRPV1-Cre:ChR2/tdTomato mice were generated by crossing TRPV1-Cre mice with ChR2/tdTomato mice (The Jackson Laboratory).

$X$-gal staining: TRPV1 ${ }^{\text {PLAP-nlacZ }}$ mice were anesthetized with isoflurane and perfused through the heart using PBS (0.1 M, pH 7.3) followed by ice-cold 2-4\% buffered paraformaldehyde. Whole skinned mice, brains, hearts, and trunk arteries were dissected and postfixed in $2-4 \%$ buffered paraformaldehyde on ice for $90 \mathrm{~min}$, after which they were washed in PBS (containing $5 \mathrm{mM}$ EGTA and $2 \mathrm{mM} \mathrm{MgCl}_{2}$ ) on ice and stained in X-gal solution (containing $1 \mathrm{mg} / \mathrm{ml} \mathrm{X-gal,} 5 \mathrm{mM}$ $\mathrm{K}_{3} \mathrm{Fe}(\mathrm{CN})_{6}, 5 \mathrm{mM} \mathrm{K} \mathrm{K}_{4} \mathrm{Fe}(\mathrm{CN})_{6}, 0.01 \%$ deoxycholate, and $2 \mathrm{mM} \mathrm{MgCl}_{2}$ in $\left.\mathrm{PBS}\right)$ at $37^{\circ} \mathrm{C}$ overnight. nLacZ staining was imaged in situ, in heart sections (120-150 $\mu \mathrm{m}$ thick) and in isolated arteries. To calculate the density of the signal, defined arteries and arterioles were isolated from TRPV1 ${ }^{\text {PLAP-nlacZ }}$ and wild-type mice, stained and photographed in parallel. 
Densitometry was performed with ImageJ to yield density in arbitrary units (normalized to the wild-type signal). To map arterial/arteriole TRPV1 expression we compared the density of X-gal staining in main trunk arteries and tributaries, heart and brain. The distribution of intensities revealed 5 broad peaks (a baseline and four positive peaks, for example see Fig. 4B) that were color-coded from zero (dark blue) to a maximum (red).

TRPVI mRNA analysis: RNA was extracted and purified using RNAqueous Micro Kit (Invitrogen). Quantitative PCR analysis was performed with Taqman Fast Advance Mastermix (Life Technologies), with TRPV1 gene probe labeled by FAM (Mm01246302_m1 from Life Technologies) and GAPDH control gene expression probe labeled by VIC (Mm99999915_g1). Thermal cycling of the PCR reaction was as follows: $50^{\circ} \mathrm{C}$ for $2 \mathrm{~min}, 95^{\circ} \mathrm{C}$ for $3 \mathrm{~min}, 50$ cycles at $95^{\circ} \mathrm{C}$ for $15 \mathrm{~s}$ and $58^{\circ} \mathrm{C}$ for $1 \mathrm{~min}$. Data were collected at the end of the $58^{\circ} \mathrm{C}$ anneal/extend step. Data were analyzed after the reaction using the Auto Ct function of the SDS 1.4 software (Life Technologies), and the reactions were considered to have passed quality control if the standard deviation of the $\mathrm{Ct}$ values were less than 0.5. The comparative $\mathrm{Ct}$ method was used to present gene expression of TRPV1 relative to GAPDH.

Immunostaining and DiOC ${ }_{18}$ labeling: Mice were anesthetized with isoflurane and perfused through the heart using PBS (0.1 M, pH 7.3) followed by ice-cold 2-4\% paraformaldehyde (in PBS). For endothelial labeling mice were perfused with the green fluorescent dye $3,3^{\prime}$ dioctadecyloxacarbocyanine perchlorate (DiOC18 ${ }_{3}$; Sigma). DiOC18 ${ }_{3}$ stock was prepared at 3 $\mathrm{mg} / \mathrm{ml}$ in $\mathrm{EtOH}$ and diluted 50x in PBS. Arteries were isolated, fixed in $4 \%$ buffered paraformaldehyde for $1.5 \mathrm{~h}$ and stored in $30 \%$ sucrose overnight. Arteries were then embedded in low temperature agarose before sectioning $(15 \mu \mathrm{m})$. Sections were stained with primary antibodies, anti-LacZ (1:100, The Developmental Studies Hybridoma Bank, University of Iowa) and anti-CD31-FITC (1:50, Biolegend) followed by a goat anti-mouse IgG-AlexaFluor 555 secondary antibody (1:300, Invitrogen). Images were acquired by confocal microscopy.

Sensory nerve culture: Dorsal root and nodose ganglia were obtained from adult mice (C57BL/6J) trimmed, digested with collagenase, and cultured in Neurobasal plus 2\% B-27 medium (Invitrogen), 0.1\% L-glutamine, and 1\% penicillin/streptomycin on poly-D-lysinecoated glass coverslips at $37^{\circ} \mathrm{C}$ in $5 \% \mathrm{CO}_{2}$. Neurons were used within $24-36 \mathrm{~h}$ of culture. 
Arterial smooth muscle (ASM) cell isolation: Radial artery branch (artery \#18, see Fig. 4G) and cerebellar branch (cerebral artery \#3, see Fig. 4G) were washed in $\mathrm{Mg}^{2+}$-based physiological saline solution (Mg-PSS) containing $5 \mathrm{mM} \mathrm{KCl}, 140 \mathrm{mM} \mathrm{NaCl}, 2 \mathrm{mM} \mathrm{MgCl}$, $10 \mathrm{mM}$ Hepes, and $10 \mathrm{mM}$ glucose $(\mathrm{pH}$ 7.3). Arteries were initially digested in papain $(0.6 \mathrm{mg} / \mathrm{ml})$ (Worthington) and dithioerythritol $(1 \mathrm{mg} / \mathrm{ml})$ in $\mathrm{Mg}$-PSS at $37^{\circ} \mathrm{C}$ for $15 \mathrm{~min}$, followed by a 15 min incubation at $37^{\circ} \mathrm{C}$ in type II collagenase $(1.0 \mathrm{mg} / \mathrm{ml})$ (Worthington) in $\mathrm{Mg}-\mathrm{PSS}$. The digested arteries were washed three times in ice-cold Mg-PSS solution and incubated on ice for $30 \mathrm{~min}$. After this incubation period, vessels were triturated to liberate smooth muscle cells and stored in ice-cold Mg-PSS before use. Smooth muscle cells adhered loosely to glass coverslips and were studied within 6 hours of isolation.

$\boldsymbol{C} \boldsymbol{a}^{2}$ imaging: ASM cells and arteries were respectively loaded with $5 \mu \mathrm{M}$ and $10 \mu \mathrm{M}$ Fluo-4-AM (Invitrogen, Thermo Fisher Scientific) in a buffer solution containing $140 \mathrm{mM} \mathrm{NaCl}, 4 \mathrm{mM} \mathrm{KCl}$, $1 \mathrm{mM} \mathrm{MgCl}_{2}, 1.2 \mathrm{mM} \mathrm{CaCl}_{2}, 10 \mathrm{mM}$ HEPES, and $5 \mathrm{mM}$ glucose (pH 7.3). Temperature was maintained at $32-35^{\circ} \mathrm{C}$ using a heated microscope stage (Tokai Hit). Bath temperature was verified by a thermistor probe (Warner instruments). ASM cells and arteries were imaged with 10X and 20X objectives using a Nikon TE2000 microscope with an excitation filter of $480 \pm 15$ $\mathrm{nm}$ and an emission filter of $535 \pm 25 \mathrm{~nm}$. The images were captured by a Retiga 3000 digital camera (QImaging) and analysis was performed offline using ImageJ.

Electrophysiology: Whole-cell patch-clamp recordings were performed using an EPC8 amplifier (HEKA). Pipette resistances were in the range 3-4 MegaOhms and the current signal was low-pass filtered at $1-3 \mathrm{kHz}$ and sampled at $4 \mathrm{kHz}$. The bath solution was the same as described for $\mathrm{Ca}^{2+}$ imaging (290 mosmol l-1). The pipette solution contained: $140 \mathrm{mM} \mathrm{CsCl,} 10$ mM Hepes, 5 mM EGTA, and $1 \mathrm{mM} \mathrm{MgCl} 2, \mathrm{pH}$ 7.3.

Ex vivo artery physiology: Skeletal muscle arteries (radial artery branch, artery \#18, subscapular branch artery \#14, gracilis artery \#29, and cerebellar branch, cerebral artery \#3, see Fig. 4G) were isolated and cannulated with glass micropipettes, and secured with monofilament threads. In some experiments arteries were denuded of endothelium by passing $1 \mathrm{ml}$ of air followed by 1 $\mathrm{ml}$ of PSS through the lumen. Effective removal of the endothelium was confirmed by the 
absence of dilation of the arteries to ACh. The pipette and bathing PSS solution (containing 125 $\mathrm{mM} \mathrm{NaCl}, 3 \mathrm{mM} \mathrm{KCl}, 26 \mathrm{mM} \mathrm{NaHCO} 3,1.25 \mathrm{mM} \mathrm{NaH}_{2} \mathrm{PO}_{4}, 1 \mathrm{mM} \mathrm{MgCl}$, 4 mM D-glucose, and $2 \mathrm{mM} \mathrm{CaCl}_{2}$, was aerated with a gas mixture consisting of $95 \% \mathrm{O}_{2}, 5 \% \mathrm{CO}_{2}$ to maintain $\mathrm{pH}$ (pH 7.4). To maximally dilate arteries we perfused a PSS solution containing $0 \mathrm{CaCl}_{2}, 0.4 \mathrm{mM}$ EGTA and $100 \mu \mathrm{M}$ sodium nitroprusside (SNP). Arterioles were mounted in a single vessel chamber (Living Systems Instrumentation) and placed on a heated imaging stage (Tokai Hit), while intraluminal pressure was maintained by a Pressure Control Station (Stratagene) at 60 mmHg. Arteries were viewed with a 10X objective using a Nikon TE2000 microscope and recorded by a digital camera (Retiga 3000, QImaging). The arteriole diameter was measured at several locations along each arteriole using the NIH-ImageJ software's edge-detection plug-in (Diameter) ${ }^{22}$. The software automatically detects the distance between edges (by resampling a total of five times from adjacent pixels) yielding a continuous read-out \pm SD of a vessel's diameter.

Coronary arterioles were visualized in sagittal tissues slices $(120-150 \mu \mathrm{m})$ prepared from the hearts of TRPV1-Cre:tdTomato mice. Slices were perfused at room temperature with the same PSS solution as for pressurized arteries.

Intravital imaging: Intravital imaging was performed in radial artery branches (about $60 \mu \mathrm{m}$ in diameter, artery \#18 in Fig 4G). Animals were anesthetized with urethane $(1.2 \mathrm{~g} / \mathrm{kg} / \mathrm{IP})$. The forelimb was shaved and an incision was made. The skin and underlying muscle tissue were reflected to expose the brachial-radial artery junction. Both in WT and TRPV1-null mice, the arteries were visualized with a Zeiss stereomicroscope and illuminated with a low power blue light (using a standard GFP filter cube) exploiting the differential auto-fluorescence between tissue and blood. In TRPV1-Cre:ChR2/tdTomato mice, arteries were visualized with low power visible irradiation and stimulated with blue light. The exposed arteries were locally perfused (using a $250 \mu \mathrm{m}$ cannula connected to a valve-controlled gravity-fed perfusion system) with preheated buffer described for $\mathrm{Ca}^{2+}$ imaging. The surface tissue temperature $\left(34-35^{\circ} \mathrm{C}\right)$ was measured via a thermistor (Warner Instruments) that was positioned next to the artery. Arteries were challenged with buffer without $\mathrm{Ca}^{2+}$ and with $1 \mathrm{mM}$ EGTA to measure the passive diameter. The arteriole diameter was measured using ImageJ as described above for the ex vivo vessels. 
Coronary flow measurements: Sprague-Dawley rats (male, 300-350 g) were placed in a deep surgical plane of anesthesia by isoflurane inhalation, confirmed by lack of pedal reflex. The heart was then exposed via thoracotomy, quickly excised and rinsed in a bath of ice-cold perfusate. The aorta was rapidly cannulated then flushed with 500 units of heparin mixed with the perfusate that contained (in $\mathrm{mM}$ ): $118 \mathrm{NaCl}, 4.7 \mathrm{KCl}, 1.25 \mathrm{CaCl}_{2}, 0.57 \mathrm{MgSO}_{4}, 1.17 \mathrm{KH}_{2} \mathrm{PO}_{4}, 25 \mathrm{NaHCO}_{3}$, and 6 glucose. Hearts were then transferred to a retrograde perfusion system that delivered oxygenated (gassed with $95 \% \mathrm{O} 2-5 \% \mathrm{CO} 2)$ perfusate to the aorta at constant pressure $(70 \mathrm{mmHg})$ and $37 \pm 1^{\circ} \mathrm{C}$. Coronary flow was measured using a tubing flowsensor (Transonic Systems) placed above the aortic cannula and was continuously acquired with the ECG using a PowerLab system (ADInstruments). Bolus injections of capsaicin were administered in-line above the aorta. BCTC was added to the perfusate reservoir. Data were analyzed off-line and the integral of coronary flow was calculated between the time of injection and the onset of the hyperemia response.

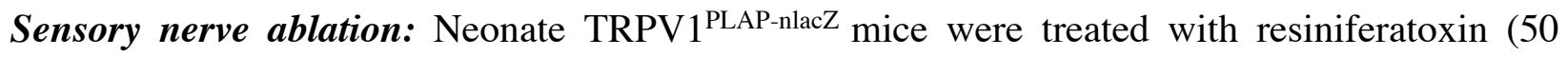
ug/kg s.c.) at postnatal days 2 and 5. Sensory nerve ablation was confirmed at 8-12 weeks of age by LacZ staining of DRG ganglia. Newborn rats (at day 14 of life) were pretreated with Diaphyllin (Richter, Hungary), Bricanyl (Astra Zeneca, Hungary), and atropine (Egis, Hungary, $100 \mathrm{~g} / 0,1 \mathrm{ml}$ i.p.). Ten minutes later animals were injected with capsaicin (subcutaneously). The procedure was repeated for a total of five consecutive days. The total dose of capsaicin was 300 $\mathrm{mg} / \mathrm{kg}$, administered on a dose schedule of $10 \mathrm{mg} / \mathrm{kg}, 20 \mathrm{mg} / \mathrm{kg} ; 50 \mathrm{mg} / \mathrm{kg} ; 100 \mathrm{mg} / \mathrm{kg}$; and 120 $\mathrm{mg} / \mathrm{kg}$ on days 1 through 5 , respectively. Rats were then kept in the animal facility for 10 weeks until experiments were performed.

Measurement of capsaicin evoked sensory irritation: One drop (10 $\mu 1)$ of capsaicin solution (50 $\mu \mathrm{g} / \mathrm{ml}$ in physiological saline) was put into the right or left conjunctiva of the rat, in a random order. The number of eye wipes was counted during $60 \mathrm{~s}$.

Systemic blood pressure recording: The experiments were performed in anesthetized mice (urethane 1.2-1.5 g/kg/IP) and rats (thiopental $50 \mathrm{mg} / \mathrm{kg} / \mathrm{IP}$; supplemented by $5 \mathrm{mg} / \mathrm{kg} / \mathrm{IV}$ if needed). After anesthesia, mice or rats underwent cannulation of the carotid artery and jugular vein as follows:

Surgical preparation in the mouse: After the depth of anesthesia was confirmed by lack 
of pedal and corneal reflexes, mice were intubated via the trachea after tracheotomy to maintain an open airway and to institute artificial respiration when necessary. Next, the left carotid artery and the right jugular vein were cannulated with a Millar catheter (1F SPR-1000) and a polyethylene tubing (PE-10), respectively, for monitoring arterial blood pressure and for systemic (intravenous) infusion of drugs. To monitor heart rate, a three-point needle electrodeassembly representing Lead II of the electrocardiogram (ECG) was attached subcutaneously to the right and left forelimbs along with a reference electrode to the left hindlimb. Both the Millar catheter and the ECG assembly were coupled to a PowerLab data acquisition system (ADInstruments). Before vessel cannulation, the adjacent left cervical vagus was carefully isolated from the left carotid artery. Body temperature was monitored by a digital rectal thermometer and maintained at $37 \pm 1^{\circ} \mathrm{C}$ with an infrared heat lamp.

Conscious blood pressure recordings: RTX-treated mice (8-12 weeks) were surgically implanted with in-dwelling jugular catheters (Instech labs., USA) $48 \mathrm{~h}$ before BP recordings. BP was measured by tail-cuff plethysmography (Coda6, Kent Scientific, USA) performed before and immediately after infusion of drugs.

Surgical preparation in the rat: Similar to the mouse, following intubation of the trachea, the left carotid artery, and jugular vein were cannulated with a polyethylene tubing (PE50) to monitor blood pressure and infuse drugs, respectively. Blood pressure (and ECG) was continuously recorded via a pressure transducer connected to the Haemosys hemodynamic system (Experimetria, Budapest, Hungary). The ECG was recorded from the extremities of the animal using hypodermic metal needles inserted subcutaneously in accordance with the Einthoven method (I, II, III leads). As in the mouse, heart rate was determined from lead II of the ECG recordings and body core temperature was maintained at $37 \pm 1{ }^{\circ} \mathrm{C}$ with a temperature controlled infrared heating lamp.

Drug administration: Intravenous infusion of drugs was initiated only when a stable baseline of blood pressure and heart rate was present. This was also the case when drugs were readministered. Final drug solutions contained: capsaicin (saline with 0.4\% EtOH), LPA (saline with $0.6 \% \mathrm{EtOH})$.

Chemicals: Capsaicin, resiniferatoxin and BCTC were purchased from Tocris Bioscience or Adooq Bioscience and stock solutions were prepared in EtOH at $1 \mathrm{M}$ and $100 \mathrm{mM}$, respectively. LPA C18:1, were purchased from Cayman Chemical. Unless otherwise indicated, all other 
chemicals were obtained from Sigma-Aldrich.

Statistical analysis: Data were analyzed using Prism (GraphPad Software, La Jolla, CA) and are expressed as means+SEM. Unless otherwise stated, statistical significance was evaluated using ttest and one-way ANOVA with treatment interactions assessed by Tukey's post hoc multiple comparisons test. 


\section{Results}

\section{TRPV1 in arteries is restricted to vascular smooth muscle}

Previous studies using antibodies have described TRPV1 expression in both vascular smooth muscle, ${ }^{23,24}$ and endothelium..$^{17,} 18$ However, the potential for non-specific labeling, well demonstrated for TRPV1 antibodies, ${ }^{24,25}$ limits the interpretation of these data. To better define arterial expression of TRPV1, we exploited two validated mouse reporter lines. The first, TRPV1-Cre:tdTomato, ${ }^{21}$ generates a very sensitive fate map of TRPV1 expression. The second, TRPV1 $1^{\text {PLAP-nlacZ }},{ }^{14}$ generates expression of human placental alkaline phosphatase (PLAP) and nuclear $\beta$-galactosidase (nLacZ) under the control of the endogenous TRPV1 promoter. Analysis of arterioles from TRPV1-Cre:tdTomato mice revealed robust tomato fluorescence in vascular smooth muscle that did not extend to the endothelium labeled with DioC18 (green, Fig. 1A). Similarly, co-labeling arteries from TRPV1 $1^{\text {PLAP-nlacZ }}$ mice with antibodies to LacZ and the endothelial marker, CD31, revealed distinct, non-overlapping staining of smooth muscle and endothelium (Fig. 1, B to E). Furthermore, we did not detect any TRPV1 reporter staining in large arteries (Fig. S1 and S2). Thus, TRPV1 expression in murine arteries appears to be restricted to vascular smooth muscle.

\section{Arteriolar TRPV1 is enriched in skeletal muscle, heart and adipose tissues}

Next, we mapped TRPV1 expression through the arterial network of the mouse. Remarkably, we found that TRPV1 was highly enriched in small (resistance) arterioles ( $<150 \mu \mathrm{m}$ diameter) of the heart, skeletal muscle and adipose tissues. In the heart, large epicardial arteries were devoid of TRPV1 expression but strong tdTomato fluorescence (Fig. 1, F and G) and nLacZ staining (Fig. 
1, $\mathrm{H}$ and I) emerged as these arteries penetrated and branched the myocardial wall. Similarly, TRPV1 expression, though mostly absent in aorta and large trunk arteries (Fig. S1), erupted as arteries branched to supply skeletal muscle (Fig. 1, J to M and Fig. S2). Indeed, analysis of skeletal muscle in whole animal (Fig. 2) or isolated tissue preparations (Fig. 1, N to Q and Fig. $\mathrm{S} 1, \mathrm{~S} 2)$ revealed an abundant network of TRPV1-expressing arteries. Note that LacZ is nuclear restricted and therefore staining excludes labeling of sensory nerve fibers. Additionally, LacZ uniformly stained vascular smooth muscle of arteries in both white and brown adipose tissue (Fig. 1, R to W). We also detected TRPV1 reporter expression in select parts of the cerebral circulation, including prominent labeling in the hypophyseal portal arteries and small-diameter branches of the basilar arteries (Fig. S3), and in very small mesenteric arteries $(<50 \mu \mathrm{m}$, Fig. S1, Q to T). In addition, microvessels or "vasa vasorum" supplying the wall of large arteries highly expressed TRPV1 (Fig. S1, B). In contrast, we found very limited TRPV1 expression in arteries of other tissues examined, including skin, lung, kidney and liver (data not shown).

Next, to confirm that TRPV1 is functionally expressed, we performed $\mathrm{Ca}^{2+}$ imaging in isolated arterioles and arteriolar smooth muscle (ASM) cells. The TRPV1-specific agonist, capsaicin, increased $\mathrm{Ca}^{2+}$ signaling in a subset of arterioles isolated from wild-type mice, whereas we observed no responses in the same arterioles from TRPV1-null mice (Fig. 3, A to D). Furthermore, capsaicin sensitivity in ASM cells isolated from TRPV1-Cre:tdTomato mice was restricted to Tomato-positive cells (Fig. 3, E and F), and was abolished after removing external $\mathrm{Ca}^{2+}$ indicating an essential role for $\mathrm{Ca}^{2+}$ entry (Fig. 3G). Finally, capsaicin $(5 \mu \mathrm{M})$ evoked inward currents in voltage-clamped isolated ASM cells (mean $8.7 \pm 2.7 \mathrm{pA} / \mathrm{pF}, \mathrm{n}=9$ ) that were fully prevented by the TRPV1 antagonist, BCTC (Fig. 3, H and I). The peak current density was $\sim 11 \%$ of that observed in cultured sensory neurons (Fig. 3, I). 
To confirm the fidelity of the TRPV1 reporter, we compared both TRPV1 mRNA levels and the capsaicin sensitivity of arteries with differential reporter expression. TRPV1 LacZ reporter expression was inversely proportional to the arterial diameter (Fig. 4B), thus we isolated arteries at different positions along the axial-brachial trunk and branches (Fig. 4A). Quantitative PCR showed that TRPV1 mRNA levels were greater in smaller diameter arterioles peaking at 13\% of DRG levels (Fig. 4C). Furthermore, results of $\mathrm{Ca}^{2+}$ imaging showed that the number of ASM cells responding to capsaicin (Fig. 4, D and E) and the magnitude of the $\mathrm{Ca}^{2+}$ signal (Fig. 4, D and F) increased in proportion to the TRPV1 reporter signal (nLacZ staining density). Based on TRPV1 reporter analysis, validated by functional imaging, we constructed a heat map of TRPV1 expression in the mouse arterial system (Fig. 4G). This map highlights the hierarchical distribution of TRPV1 becoming abundant in small-diameter resistance arterioles of skeletal muscle and heart (adipose is not represented here).

\section{TRPV1 constricts arterioles $e x$ vivo and in vivo}

To identify a physiological role for vascular TRPV1, we studied contractility in isolated, pressurized arteries. Capsaicin $(1 \mu \mathrm{M}$ ) constricted (by $\sim 80-85 \%$ ) arterioles isolated from wildtype (Fig. 5, A and B) and TRPV1-Cre:tdTomato mice (Fig. S4, A and B) without affecting vessels from TRPV1-null mice. Analysis of the response to varying capsaicin concentrations revealed a half-maximal effect at $\sim 150 \mathrm{nM}$ that was unaffected by removing the vascular endothelium (Fig. 5C and Fig. S4, C to E), consistent with a selective action of capsaicin at arterial smooth muscle. To measure the in vivo functionality of arterial TRPV1, we performed intravital imaging of radial branch arteries. Local administration of capsaicin constricted these arteries (by $\sim 90 \%$ ) without affecting nearby veins, or arteries in TRPV1-null mice (Fig. 5, D and E, Fig. S4 F and G, and Movies 1, 2). As an additional test of functional arterial TRPV1 
expression, we generated mice expressing channelrhodopsin-2 (ChR2) under the control of TRPV1 gene regulatory elements (TRPV1-Cre:ChR2/tdTomato mice) to enable photo-control of cells expressing TRPV1. Control experiments revealed that expression of the TRPV1-Cre reporter and therefore ChR2, accurately reflect contemporaneous TRPV1 expression (Fig. S4A). Blue light rapidly and reversibly constricted arterioles in these animals, in both ex vivo and in vivo preparations, without affecting the caliber of the veins (Fig. 5E and Fig. S4, A and B) or arteries from TRPV1-Cre ${ }^{-/-}$mice (data not shown). Thus, optogenetic sensitivity of arteries confirms TRPV1 expression in vascular smooth muscle, and can be exploited to control vessel diameter.

Finally, we tested the relative contribution of $\mathrm{Ca}^{2+}$ entry via TRPV1 or voltage-gated channel channels. Indeed, the L-type voltage-gated $\mathrm{Ca}^{2+}$ channel (Cav1.2) is a major determinant of resting tone in arterioles. We found that nifedipine $(3 \mu \mathrm{M})$ relaxed in vivo arterioles, but only partly (by $\sim 30 \%$ ) inhibited the constriction evoked by a saturating concentration of capsaicin (Fig. 5F), indicating that $\mathrm{Ca}^{2+}$ influx through fully-activated TRPV1 channels is sufficient to constrict arteries, while L-type channels amplify the magnitude of the constriction. Figure 5G, summarizes the signaling pathways for TRPV1-mediated vasoconstriction; $\mathrm{Ca}^{2+}$ entry via TRPV1 and depolarization evoked $\mathrm{Ca}^{2+}$ entry via Cav1.2.

\section{TRPV1 constricts coronary arterioles and decreases coronary flow}

The striking expression of TRPV1 in the coronary vasculature (Fig. 1) prompted us to explore functional effects of TRPV1 activation. Analysis of heart sections from TRPV1 reporter mice (Fig. 6, A and B) revealed that TRPV1 expression is restricted to small arterioles that branch from the large coronary arteries (yellow arrowheads). Application of capsaicin $1 \mu \mathrm{M}$ to sagittal slice preparations $(\sim 150 \mu \mathrm{m})$ of living heart tissue constricted these small arterioles and the 
magnitude of the response was inversely proportional to artery diameter (Fig. 6, C to E). Next, we examined a role for TRPV1 in the regulation of coronary flow in isolated rat hearts. Administration of capsaicin (by $10 \mathrm{~s}$ in-line infusion) decreased flow in a dose-dependent manner, followed by a rebound hyperemia (Fig. 6, $\mathrm{F}$ to $\mathrm{H}$ ). The decrease in flow occurred without a change in heart rate and was fully prevented by pretreatment with BCTC.

\section{Arterial TRPV1 regulates systemic blood pressure}

The extensive expression in arteriolar smooth muscle makes TRPV1 well situated to influence systemic blood pressure (BP). We therefore tested whether TRPV1 agonists would alter BP as predicted by their profound vasoconstrictive effects detailed above. Indeed, intravenous (IV) administration of capsaicin to anesthetized mice markedly increased BP, while TRPV1-null mice exhibited no responses to capsaicin demonstrating a selective action at TRPV1 (Fig. 7, A and B and Fig. S5, A to C). Further, we observed equivalent BP responses to capsaicin in conscious mice (Fig. 5I and Fig. S5H) ruling out side effects of anesthesia. Similarly, in rats, capsaicin produced a dose-dependent increase in BP with an approximate $60 \mathrm{mmHg}$ rise in systolic and diastolic blood pressure observed at the highest dose tested, (Fig. 7C, Fig. S5, K to M). The peak responses to capsaicin occurred without any significant changes in heart rate (Fig. S5, D, G, I, N and $\mathrm{P}$ ), demonstrating a predominant effect on peripheral vascular resistance.

Although the pressor response to capsaicin is consistent with actions at arterial TRPV1, these data do not exclude a contribution of TRPV1 in perivascular sensory nerves. TRPV1-expressing nerves may affect blood flow by releasing vasoactive peptides such as CGRP ${ }^{26}$ or neurokinins. 19, 20 Therefore, to discriminate between an arterial and neurogenic locus of TRPV1 signaling, we performed selective ablation of TRPV1-expressing sensory nerves. Resiniferatoxin or capsaicin administered systemically to neonates causes permanent deletion of most TRPV1-positive 
sensory nerves. ${ }^{27,} 28$ In contrast, TRPV1-expressing arterial smooth muscle exhibits full functional recovery from this treatment, ${ }^{29}$ reflecting differences between neurons and vascular smooth muscle cells. Indeed, 8 weeks following RTX administration to TRPV1-nLacZ mice, we observed an almost complete loss of nLacZ staining in DRG neurons, whereas arterial staining was unaffected (Fig. 7D and Fig. S5E). Similarly, treating neonatal rats with capsaicin abolished subsequent nocifensive responses (eye-wipes) to capsaicin (Fig. 7E) consistent with ablation of TRPV1 expressing sensory neurons. Notably, administration of capsaicin to these sensory-nerve ablated mice (Fig. 7G and Fig. S5, F and H) and rats (Fig. 7H and Fig. S5O) evoked pressor responses similar to untreated controls. Thus, we conclude that sensory nerves play little to no role in the capsaicin-evoked BP rise.

In previous studies, capsaicin was shown to elicit a cardiopulmonary Bezold-Jarisch reflex consisting of a transient drop in BP, bradycardia and apnea. ${ }^{30}$ Indeed, we observed that capsaicin evoked a fast, transient depressor response that preceded the rise in BP (see arrowhead in Fig. 7A). At doses $<4 \mu \mathrm{g} / \mathrm{kg}$, bolus capsaicin only produced this transient depressor response accompanied by a decrease in heart rate (Fig. 7, J to L). At higher doses (from $8 \mu \mathrm{g} / \mathrm{kg}$ capsaicin), an additional pressor response emerged (Fig. 7J). Notably, pretreatment with atropine or sensory nerve ablation eliminated this transient depressor response to capsaicin, consistent with it being mediated by the vagus nerve, and unmasked the arteriolar TRPV1 mediated increase in BP.

\section{Lysophosphatidic acid constricts arterioles and increases blood pressure via TRPV1}

Next, we tested the potential physiological function of vascular TRPV1. We hypothesized that the vasoconstrictive effect of some endogenous bioactive lipids is mediated by TRPV1 activation. We examined lysophosphatidic acids (LPA), a vasoconstrictor lipid species generated 
by platelets and atherogenic plaques, ${ }^{31,32}$ potentially activating TRPV $1 .^{33}$ Notably, LPA species containing an unsaturated acyl chain are potent vasoconstrictors but whether cognate GPCRs for LPA (LPA $1-6$ ) mediate these effects is uncertain. ${ }^{31,34}$ We found that LPA (C18:1) constricted skeletal muscle arterioles isolated from WT but not from TRPV1-null mice confirming a selective action at TRPV1 (Fig. 5, A and B). Furthermore, systemic administration of LPA (60 $\mu \mathrm{g} / \mathrm{kg}$ ) triggered a Bezold-Jarisch reflex and an increase in BP in a TRPV1-dependent manner (Fig. 7, A and B and Fig. S5, A to C). These data agree with previous observations that LPA exerts a pressor effect in several mammals (cats, rats, and guinea pigs) but notably not in rabbits, ${ }^{35,36}$ that possess a hypofunctional TRPV1 channel. ${ }^{37}$ In summary, our data show that TRPV1 contributes to the regulation of arteriolar tone and systemic BP by mediating vasoconstrictive responses to the inflammatory lipid LPA.

\section{Vascular TRPV1 is resistant to desensitization and mediates a persistent increase in blood pressure}

In sensory nerves, TRPV1 ordinarily exhibits pronounced desensitization to agonists, reflected by a diminishing current response to repeated (tachyphylaxis) or sustained agonist application. ${ }^{38,}$

${ }^{39}$ Indeed, in voltage-clamped sensory neurons we found that the response to these forms of capsaicin application declined rapidly to less than $20 \%$ of the initial current (Fig. 8, A and C). In contrast, in isolated arterial smooth muscle cells, capsaicin evoked non-declining currents; the current response to the fourth application was $110 \%$ of the first application and there was no evident current decay during sustained treatment (Fig. 8, B and C). Similarly, repetitive or prolonged (5 - 20 minutes) systemic administration of capsaicin to mice evoked reproducible and sustained increases in BP (Fig. 8, D to G and Fig. S6). These pressor effects were unaffected by 
ablation of sensory nerves (Fig. 8G) and occurred without changes in heart rate upon the elevated BP (Fig. 8 E, F and I), reflecting a primary action of TRPV1 located in vascular myocytes. Finally, we tested whether LPA could generate persistent BP responses. Similar to capsaicin, slow infusion of LPA $(\mathrm{C} 18: 1,75 \mu \mathrm{g} / \mathrm{kg} / \mathrm{min})$ produced sustained increases in BP without affecting heart rate (Fig. 8 F, H, and I). 


\section{Discussion}

TRPV1 is an ion channel with important roles in somatosensory transduction. ${ }^{2,12}$ Our data reveal extensive expression of TRPV1 in the arterial circulation. Using combined molecular and functional analyses we found that TRPV1 localizes to the smooth muscle of arterioles supplying skeletal muscle, heart and adipose tissues. Notably, we did not detect TRPV1 in vascular endothelium and removal of endothelium had no effect on the efficacy/potency for capsaicin to constrict arteries. Furthermore, our analysis shows that TRPV1 predominates in small-diameter $(<150 \mu \mathrm{m})$ arteries and is practically absent in large vessels. Quantitative mRNA measurements showed that TRPV1 expression in small arterioles is $\sim 13 \%$ of DRG levels. Similarly, the peak capsaicin-evoked current density in arterial smooth muscle cells was $\sim 11 \%$ of that recorded in sensory neurons. Several pertinent observations can be made about TRPV1 expression in vascular smooth muscle. First, given the extensive network of arteries in muscle and adipose tissues then the overall level of TRPV1 protein in the vasculature likely exceeds that in nerves. Second, activation of TRPV1 even at low levels, was nonetheless capable of markedly constricting skeletal muscle arteries, both ex vivo and in vivo, and coronary arteries leading to reduced coronary perfusion. The L-type $\mathrm{Ca}^{2+}$ channel (CaV1.2) blocker, nifedipine, only partly inhibited the response to a saturating concentration of capsaicin, indicating that $\mathrm{Ca}^{2+}$ entry via maximally activated TRPV1 per se can support constriction while depolarization induced activation of CaV1.2 amplifies the response. The amplification may become prominent during submaximal activation of TRPV1.

We found that systemic administration of TRPV1 agonists elicited large increases in BP. This pressor effect occurred without significant changes in heart rate and is consistent with a 
vasoconstrictor action of TRPV1. Although TRPV1-expressing sensory nerves, through the release of vasoactive peptides, could contribute to changes in $\mathrm{BP}$, we found the pressor response was independent of neurogenic regulation. First, we studied mice and rats treated after birth with RTX or capsaicin to ablate the TRPV1-positive sensory nerve population. TRPV1 in the vasculature of these animals exemplified complete recovery when measured at 8-10 weeks, reflecting lower toxicity and /or replacement of nascent arterial smooth muscle cells. Notably, the $\mathrm{BP}$ response to capsaicin in these nerve-ablated animals was unchanged compared with control animals indicating that sensory nerves do not significantly contribute to TRPV1mediated BP regulation. One exception to this result was the presence of a fast depressor response to capsaicin, most evident upon bolus administration. This BP decrease, accompanied by decreased heart rate and apnea, likely reflects the Bezold-Jarisch reflex, ${ }^{30}$ and was abolished after sensory nerve ablation or after atropine treatment to inhibit vagal cholinergic responses. Second, we found that TRPV1 channels in ASM cells resist desensitization in response to capsaicin stimulation. Significantly, this effect was recapitulated in systemic BP recordings where infusions of TRPV1 agonists produced sustained increases in BP without desensitization. Furthermore, during repetitive capsaicin treatment we observed that the Bezold-Jarisch reflex was evident only upon the first administration consistent with a pronounced desensitization of sensory nerves. Thus taken together, the sustained increases in BP correlate with the persistent opening of TRPV1 channels in ASM cells and not with the transient TRPV1 response in sensory nerves. Our finding that sensory nerves play little role in the persistent capsaicin regulation of BP may seem surprising, but is consistent with the plethora of earlier studies showing that sensory nerves primarily trigger dilation rather than constriction of arterioles, and that this effect is especially evident in the skin and other epithelial tissues. ${ }^{19,20}$ Similarly, capsaicin triggers marked 
plasma extravasation (measured by Evans Blue) that is restricted to the skin, airways, and urogenital organs, that have prominent perivascular sensory nerves, and neurogenic inflammation is absent throughout the remainder of the circulation including brain, skeletal muscle and the heart. ${ }^{19,40}$ Thus, any neurogenic vasodilatory action in response to systemic capsaicin would be swamped by the direct vasoconstrictor effects in arterioles.

What processes allow vascular smooth muscle TRPV1 to resist desensitization? Desensitization of TRPV1 is both $\mathrm{Ca}^{2+}$ and state dependent. In sensory nerves the removal of external $\mathrm{Ca}^{2+}$ ions abolishes capsaicin-induced desensitization consistent with a key role for $\mathrm{Ca}^{2+}$ signaling. ${ }^{38,39}$ Direct binding of calmodulin, ${ }^{41} \mathrm{Ca}^{2+}$-induced dephosphorylation, ${ }^{42,}{ }^{43}$ or $\mathrm{Ca}^{2+}$-dependent hydrolysis of phosphatidylinositol 4,5-bisphosphate $\left(\mathrm{PIP}_{2}\right),{ }^{44,45}$ have all been proposed as potential mechanisms. Structural changes in the TRPV1 channel may underlie desensitization. Evidence in support of this is provided by studies of the ultrapotent agonist, RTX, and doubleknot spider toxin (DkTx) that do not induce desensitization even in the presence of external $\mathrm{Ca}^{2+}$. The results of cryo-EM analysis, ${ }^{4}$ suggests that binding of RTX/DkTx stabilizes displacement of the pore helix which is a mobile element in gating, to produce sustained channel opening. In contrast, capsaicin does not stabilize movement of the pore helix, but instead engages the lower channel gate, ${ }^{4}$ leading to the appearance of flickery channel openings, ${ }^{46}$ that may facilitate the transition to desensitized states. Thus, in arteries resistance to capsaicin-induced desensitization may arise from modifications to the TRPV1 channel protein, or alternatively, the existence of different $\mathrm{Ca}^{2+}$ signaling pathways, but further studies are needed to understand the precise underlying mechanisms. 
TRPV1 plays a critical role in pain signaling; diverse inflammatory mediators activate or sensitize TRPV1 located in sensory nerves to enhance nociception. ${ }^{1,2,47}$ Our data reveal that TRPV1 agonists, including capsaicin and LPA, act on arterial TRPV1 to mediate vasoconstriction and a sustained increase in systemic BP. Notably, LPA is produced by platelets and artherogenic plaques, ${ }^{31,32}$ and is elevated in acute coronary syndrome, ${ }^{48,49}$ associated with vasospasm of small coronary arteries. TRPV1 in the coronary microcirculation may therefore represent a prime target for mediating this vasoconstriction. Further, autotaxin, the rate-limiting enzyme for LPA production, is secreted abundantly by adipocytes,${ }^{50}$ bringing the synthesis of LPA in close proximity to adipose arteries that highly express TRPV1. Notably, several lipoxygenase-dependent metabolites of arachidonic acid are potent TRPV1 agonists, including 12- and 15-(S)-HPETE, 5-(S)- and 5-(R)-hydroxyeicosatetraenoic acid (5- $(S)$-HETE and 5- $(R)$ HETE), 12-(S)-HETE, and leukotriene $\mathrm{B}_{4},{ }^{51}$ and may therefore be capable of constricting TRPV1-expressing arteries. Genetic studies also support a fundamental role for TRPV1 in the regulation of blood flow. Indeed, disrupting TRPV1 gene expression exacerbates ischemic reperfusion injury in the heart. ${ }^{52}$ Furthermore, in experimentally induced sepsis, TRPV1-null mice exhibit both a greater fall in BP and higher mortality than their wild-type counterparts, ${ }^{53-56}$ suggesting that TRPV1-mediated vasoconstriction during inflammation contributes to the homeostatic regulation of BP. Collectively, these observations indicate potentially important roles for TRPV1 in regulating vasoconstriction and BP in disease and injury states. 
Acknowledgments: We thank R. Gillis and R. Miyares for comments on the manuscript. Funding: This study was supported by National Institute of Diabetes and Digestive and Kidney Diseases Grant U01 DK-101040 (G.A.), the Hungarian Research Fund (OTKA K116940 to RP and AT) and by the GINOP-2.3.2-15-2016-00043 and GINOP-2.3.2-15-2016-00050 grants (to AT). The project is co-financed by the European Union and the European Regional Development Fund. Hajnalka Gulyás was supported by Gedeon Richter Talentum Foundation (Hungary, Budapest 1103, Gyömrői str. 19.-21.)

Author contributions: T.P designed and performed most of the experiments, analyzed the data and helped write the manuscript; G.A. conceived and designed experiments, performed electrophysiology and wrote the manuscript; H.T. performed experiments; N.S. assisted with mouse BP measurements and helped write the manuscript; H.G and R.B. performed rat physiology and helped write the manuscript. A.T. helped design experiments and helped write the manuscript. R.R. and M.K. performed coronary flow experiments.

Disclosures: T.P and G.A are co-inventors of a provisional patent application related to technology presented in this manuscript. 


\section{References}

1. Szallasi A and Blumberg PM. Vanilloid (Capsaicin) receptors and mechanisms. Pharmacol Rev. 1999;51:159-212.

2. Caterina MJ and Julius D. The vanilloid receptor: a molecular gateway to the pain pathway. Annu Rev Neurosci. 2001;24:487-517.

3. Bohlen CJ, Priel A, Zhou S, King D, Siemens J and Julius D. A bivalent tarantula toxin activates the capsaicin receptor, TRPV1, by targeting the outer pore domain. Cell. 2010;141:834-45.

4. Cao E, Liao M, Cheng Y and Julius D. TRPV1 structures in distinct conformations reveal activation mechanisms. Nature. 2013;504:113-8.

5. Liao M, Cao E, Julius D and Cheng Y. Structure of the TRPV1 ion channel determined by electron cryo-microscopy. Nature. 2013;504:107-12.

6. Gao Y, Cao E, Julius D and Cheng Y. TRPV1 structures in nanodiscs reveal mechanisms of ligand and lipid action. Nature. 2016;534:347-51.

7. Caterina MJ, Schumacher MA, Tominaga M, Rosen TA, Levine JD and Julius D. The capsaicin receptor: a heat-activated ion channel in the pain pathway. Nature. 1997;389:816-24.

8. Tominaga M, Caterina MJ, Malmberg AB, Rosen TA, Gilbert H, Skinner K, Raumann $\mathrm{BE}$, Basbaum AI and Julius D. The cloned capsaicin receptor integrates multiple painproducing stimuli. Neuron. 1998;21:531-43.

9. Davis JB, Gray J, Gunthorpe MJ, Hatcher JP, Davey PT, Overend P, Harries MH, Latcham J, Clapham C, Atkinson K, Hughes SA, Rance K, Grau E, Harper AJ, Pugh PL, Rogers DC, Bingham S, Randall A and Sheardown SA. Vanilloid receptor-1 is essential for inflammatory thermal hyperalgesia. Nature. 2000;405:183-7.

10. Caterina MJ, Leffler A, Malmberg AB, Martin WJ, Trafton J, Petersen-Zeitz KR, Koltzenburg M, Basbaum AI and Julius D. Impaired nociception and pain sensation in mice lacking the capsaicin receptor. Science. 2000;288:306-13.

11. Szallasi A, Cortright DN, Blum CA and Eid SR. The vanilloid receptor TRPV1: 10 years from channel cloning to antagonist proof-of-concept. Nat Rev Drug Discov. 2007;6:357-72.

12. Bautista DM, Wilson SR and Hoon MA. Why we scratch an itch: the molecules, cells and circuits of itch. Nature Publishing Group. 2014;17:175-182.

13. Yarmolinsky DA, Peng Y, Pogorzala LA, Rutlin M, Hoon MA and Zuker CS. Coding and Plasticity in the Mammalian Thermosensory System. Neuron. 2016;92:1079-1092.

14. Cavanaugh DJ, Chesler AT, Jackson AC, Sigal YM, Yamanaka H, Grant R, O'Donnell D, Nicoll RA, Shah NM, Julius D and Basbaum AI. Trpv1 reporter mice reveal highly restricted brain distribution and functional expression in arteriolar smooth muscle cells. J Neurosci. 2011;31:5067-77.

15. Kark T, Bagi Z, Lizanecz E, Pásztor ET, Erdei N, Czikora A, Papp Z, Edes I, Pórszász R and Tóth A. Tissue-specific regulation of microvascular diameter: opposite functional roles of neuronal and smooth muscle located vanilloid receptor-1. Molecular pharmacology. 2008;73:1405-12.

16. Phan TX, Ton HT, Chen Y, Basha ME and Ahern GP. Sex-dependent expression of TRPV1 in bladder arterioles. American journal of physiology Renal physiology. 2016;311:F1063-F1073. 
17. Bratz IN, Dick GM, Tune JD, Edwards JM, Neeb ZP, Dincer UD and Sturek M. Impaired capsaicin-induced relaxation of coronary arteries in a porcine model of the metabolic syndrome. American journal of physiology Heart and circulatory physiology. 2008;294:H2489-96.

18. Yang D, Luo Z, Ma S, Wong WT, Ma L, Zhong J, He H, Zhao Z, Cao T, Yan Z, Liu D, Arendshorst WJ, Huang Y, Tepel M and Zhu Z. Activation of TRPV1 by dietary capsaicin improves endothelium-dependent vasorelaxation and prevents hypertension. Cell metabolism. 2010;12:130-41.

19. Baluk P. Neurogenic inflammation in skin and airways. The journal of investigative dermatology Symposium proceedings. 1997;2:76-81.

20. Holzer P. Neurogenic vasodilatation and plasma leakage in the skin. General pharmacology. 1998;30:5-11.

21. Mishra SK, Tisel SM, Orestes P, Bhangoo SK and Hoon MA. TRPV1-lineage neurons are required for thermal sensation. EMBO J. 2011;30:582-93.

22. Fischer MJM, Uchida S and Messlinger K. Measurement of meningeal blood vessel diameter in vivo with a plug-in for ImageJ. Microvascular research. 2010;80:258-66.

23. Lizanecz E, Bagi Z, Pásztor ET, Papp Z, Edes I, Kedei N, Blumberg PM and Tóth A. Phosphorylation-dependent desensitization by anandamide of vanilloid receptor-1 (TRPV1) function in rat skeletal muscle arterioles and in Chinese hamster ovary cells expressing TRPV1. Molecular pharmacology. 2006;69:1015-23.

24. Toth A, Czikora A, Pasztor ET, Dienes B, Bai P, Csernoch L, Rutkai I, Csato V, Manyine IS, Porszasz R, Edes I, Papp Z and Boczan J. Vanilloid Receptor-1 (TRPV1) Expression and Function in the Vasculature of the Rat. Journal of Histochemistry \& Cytochemistry. 2014;62:129-144.

25. Sand CA, Grant AD and Nandi M. Vascular Expression of Transient Receptor Potential Vanilloid 1 (TRPV1). Journal of Histochemistry \& Cytochemistry. 2015;63:449-453. 26. Zygmunt PM, Petersson J, Andersson DA, Chuang H, Sorgard M, Di Marzo V, Julius D and Hogestatt ED. Vanilloid receptors on sensory nerves mediate the vasodilator action of anandamide. Nature. 1999;400:452-7.

27. Jancsó G, Kiraly E and Jancsó-Gábor A. Pharmacologically induced selective degeneration of chemosensitive primary sensory neurones. Nature. 1977;270:741-3.

28. Szallasi A and Blumberg PM. Vanilloid receptor loss in rat sensory ganglia associated with long term desensitization to resiniferatoxin. Neuroscience letters. 1992;140:51-4.

29. Czikora Á, Rutkai I, Pásztor ET, Szalai A, Pórszász R, Boczán J, Édes I, Papp Z and Tóth A. Different Desensitization Patterns for Sensory and Vascular TRPV1 Populations in the Rat: Expression, Localization and Functional Consequences. PloS one. 2013;8:e78184. 30. Szolcsanyi J, Szallasi A, Szallasi Z, Joo F and Blumberg PM. Resiniferatoxin: an ultrapotent selective modulator of capsaicin-sensitive primary afferent neurons. The Journal of pharmacology and experimental therapeutics. 1990;255:923-8.

31. Panchatcharam M, Miriyala S, Yang F, Rojas M, End C, Vallant C, Dong A, Lynch K, Chun J, Morris AJ and Smyth SS. Lysophosphatidic acid receptors 1 and 2 play roles in regulation of vascular injury responses but not blood pressure. Circulation Research. 2008;103:662-70.

32. Cui M-Z. Lysophosphatidic acid effects on atherosclerosis and thrombosis. Clinical lipidology. 2011;6:413-426. 
33. Nieto-Posadas A, Picazo-Juárez G, Llorente I, Jara-Oseguera A, Morales-Lázaro S, Escalante-Alcalde D, Islas LD and Rosenbaum T. Lysophosphatidic acid directly activates TRPV1 through a C-terminal binding site. Nature Chemical Biology. 2011;8:78-85.

34. Kano K, Matsumoto H, Inoue A, Yukiura H, Kanai M, Chun J, Ishii S, Shimizu T and Aoki J. Molecular mechanism of lysophosphatidic acid-induced hypertensive response. Scientific Reports. 2019:1-12.

35. Tokumura A, Fukuzawa K and Tsukatani H. Effects of synthetic and natural lysophosphatidic acids on the arterial blood pressure of different animal species. Lipids. 1978;13:572-4.

36. Tokumura A, Maruyama T, Fukuzawa K and Tsukatani H. Effects of lysophosphatidic acids and their structural analogs on arterial blood pressure of cats. ArzneimittelForschung. 1985;35:287-92.

37. Gavva NR, Klionsky L, Qu Y, Shi L, Tamir R, Edenson S, Zhang TJ, Viswanadhan VN, Toth A, Pearce LV, Vanderah TW, Porreca F, Blumberg PM, Lile J, Sun Y, Wild K, Louis J-C and Treanor JJS. Molecular determinants of vanilloid sensitivity in TRPV1. The Journal of biological chemistry. 2004;279:20283-95.

38. Dray A, Bettaney J and Forster P. Capsaicin desensitization of peripheral nociceptive fibres does not impair sensitivity to other noxious stimuli. Neuroscience letters. 1989;99:50-4.

39. Koplas PA, Rosenberg RL and Oxford GS. The role of calcium in the desensitization of capsaicin responses in rat dorsal root ganglion neurons. J Neurosci. 1997;17:3525-37.

40. Saria A, Lundberg JM, Skofitsch G and Lembeck F. Vascular protein linkage in various tissue induced by substance $P$, capsaicin, bradykinin, serotonin, histamine and by antigen challenge. Naunyn Schmiedebergs Arch Pharmacol. 1983;324:212-8.

41. Numazaki M, Tominaga T, Takeuchi K, Murayama N, Toyooka H and Tominaga M. Structural determinant of TRPV1 desensitization interacts with calmodulin. Proceedings of the National Academy of Sciences of the United States of America. 2003;100:8002-6.

42. Jung J, Shin JS, Lee S-Y, Hwang SW, Koo J, Cho H and Oh U. Phosphorylation of vanilloid receptor 1 by Ca2+/calmodulin-dependent kinase II regulates its vanilloid binding. The Journal of biological chemistry. 2004;279:7048-54.

43. Mohapatra DP and Nau C. Regulation of Ca2+-dependent desensitization in the vanilloid receptor TRPV1 by calcineurin and cAMP-dependent protein kinase. The Journal of biological chemistry. 2005;280:13424-32.

44. Yao J and Qin F. Interaction with Phosphoinositides Confers Adaptation onto the TRPV1 Pain Receptor. PLoS Biology. 2009; 7:e1000046.

45. Lukacs V, Yudin Y, Hammond GR, Sharma E, Fukami K and Rohacs T. Distinctive Changes in Plasma Membrane Phosphoinositides Underlie Differential Regulation of TRPV1 in Nociceptive Neurons. The Journal of neuroscience : the official journal of the Society for Neuroscience. 2013;33:11451-11463.

46. Hui K, Liu B and Qin F. Capsaicin activation of the pain receptor, VR1: multiple open states from both partial and full binding. Biophysical journal. 2003;84:2957-68.

47. Basbaum AI, Bautista DM, Scherrer G and Julius D. Cellular and molecular mechanisms of pain. Cell. 2009;139:267-84.

48. Dohi T, Miyauchi K, Ohkawa R, Nakamura K, Kishimoto T, Miyazaki T, Nishino A, Nakajima N, Yaginuma K, Tamura H, Kojima T, Yokoyama K, Kurata T, Shimada K, Yatomi Y and Daida H. Increased circulating plasma lysophosphatidic acid in patients with acute 
coronary syndrome. Clinica chimica acta; international journal of clinical chemistry. 2012;413:207-12.

49. Kurano M, Suzuki A, Inoue A, Tokuhara Y, Kano K, Matsumoto H, Igarashi K, Ohkawa R, Nakamura K, Dohi T, Miyauchi K, Daida H, Tsukamoto K, Ikeda H, Aoki J and Yatomi Y. Possible involvement of minor lysophospholipids in the increase in plasma lysophosphatidic acid in acute coronary syndrome. Arteriosclerosis, thrombosis, and vascular biology. 2015;35:463-70.

50. Dusaulcy R, Rancoule C, Grès S, Wanecq E, Colom A, Guigné C, Van Meeteren LA, Moolenaar WH, Valet P and Saulnier-Blache JS. Adipose-specific disruption of autotaxin enhances nutritional fattening and reduces plasma lysophosphatidic acid. Journal of Lipid Research. 2011;52:1247-1255.

51. Hwang SW, Cho H, Kwak J, Lee SY, Kang CJ, Jung J, Cho S, Min KH, Suh YG, Kim D and Oh U. Direct activation of capsaicin receptors by products of lipoxygenases: Endogenous capsaicin-like substances. Proc Natl Acad Sci U S A. 2000;97:6155-6160.

52. Wang L and Wang DH. TRPV1 gene knockout impairs postischemic recovery in isolated perfused heart in mice. Circulation. 2005;112:3617-23.

53. Clark N, Keeble J, Fernandes ES, Starr A, Liang L, Sugden D, de Winter P and Brain SD. The transient receptor potential vanilloid 1 (TRPV1) receptor protects against the onset of sepsis after endotoxin. FASEB journal : official publication of the Federation of American Societies for Experimental Biology. 2007;21:3747-55.

54. Wang Y, Novotny M, Quaiserová-Mocko V, Swain GM and Wang DH. TRPV1mediated protection against endotoxin-induced hypotension and mortality in rats. American journal of physiology Regulatory, integrative and comparative physiology. 2008;294:R1517-23.

55. Guptill V, Cui X, Khaibullina A, Keller JM, Spornick N, Mannes A, Iadarola M and Quezado ZMN. Disruption of the transient receptor potential vanilloid 1 can affect survival, bacterial clearance, and cytokine gene expression during murine sepsis. Anesthesiology. 2011;114:1190-9.

56. Fernandes ES, Liang L, Smillie S-J, Kaiser F, Purcell R, Rivett DW, Alam S, Howat S, Collins H, Thompson SJ, Keeble JE, Riffo-Vasquez Y, Bruce KD and Brain SD. TRPV1 deletion enhances local inflammation and accelerates the onset of systemic inflammatory response syndrome. Journal of immunology (Baltimore, Md : 1950). 2012;188:5741-51. 

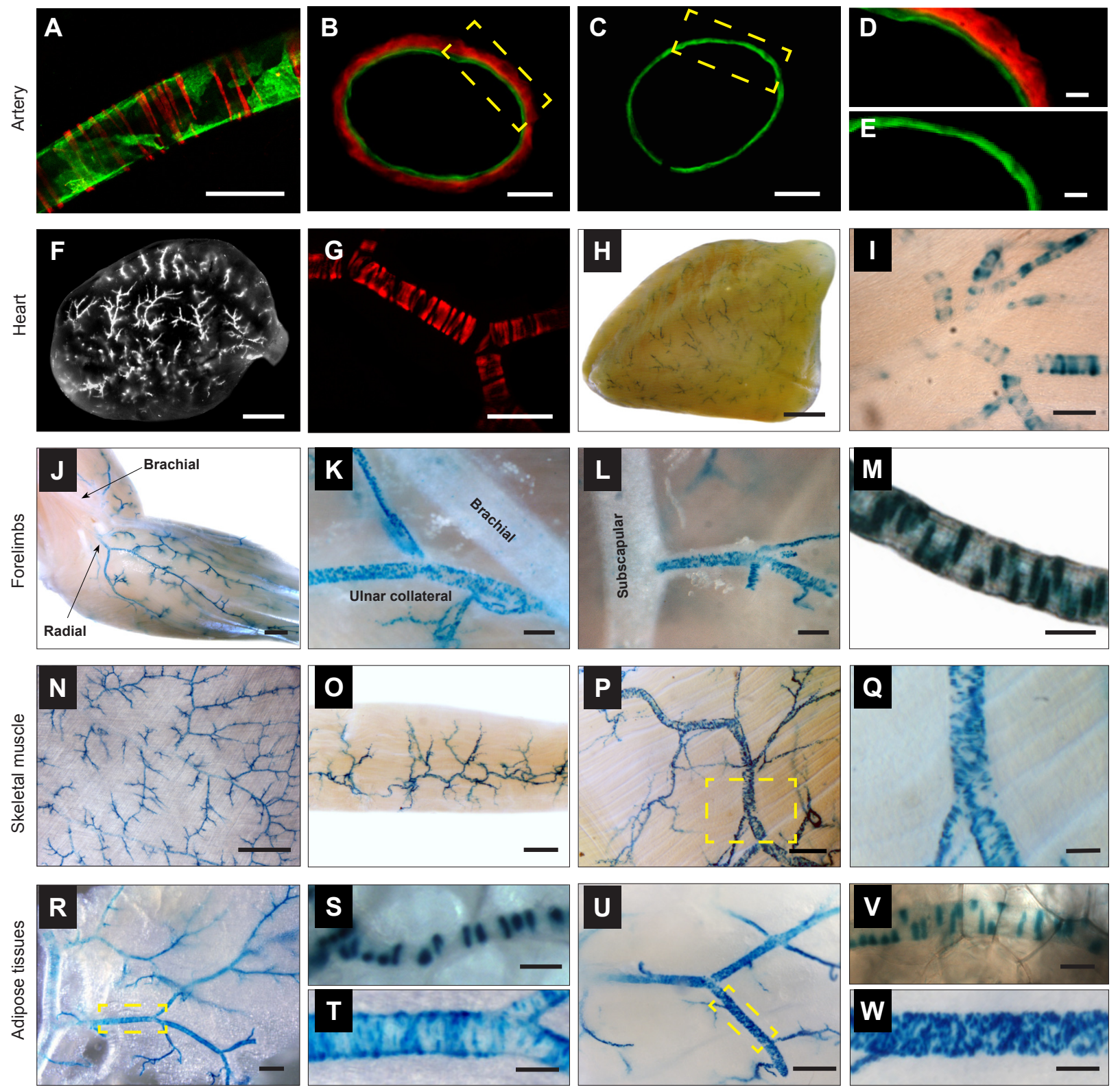

Figure 1. TRPV1 reporter mice reveal expression of TRPV1 in vascular smooth muscle of myocardium, skeletal muscle and fat. (A), TdTomato fluorescence in a muscle artery from a TRPV1-Cre:Tomato mouse. (B, D), Endothelium is stained with DioC18 (green). LacZ and CD31 immunostaining in artery cross-sections from a TRPV1 ${ }^{\text {PLAP-nlacZ }}$ and $(\mathbf{C}, \mathbf{E})$, WT mouse. $(\mathbf{F}$, G), Analysis of whole hearts and transverse heart sections from TRPV1-Cre:tdTomato or (H, I), TRPV1 $1^{\text {PLAP-nlacZ }}$ mice reveals TRPV1 expression in small arterioles of the ventricular myocardium. (J-M), Nuclear LacZ staining in forelimb arteries, $(\mathbf{N})$, latissimus dorsi, $(\mathbf{O})$, gracilis and $(\mathbf{P}, \mathbf{Q})$, trapezius skeletal muscles, and arteries supplying $(\mathbf{R}$ to $\mathbf{T})$, white and (U to $\mathbf{W}$ ), brown adipose tissues. Insets (yellow boxes) in $\mathbf{P}, \mathbf{R}$ and $\mathbf{U}$ are expanded in $\mathbf{Q}, \mathbf{T}$ and $\mathbf{W}$ respectively. Scale bar: $1 \mathrm{~mm}(\mathrm{~F}, \mathrm{H}, \mathrm{J}, \mathrm{N}) ; 300 \mu \mathrm{m}(\mathrm{O}, \mathrm{K}, \mathrm{R}, \mathrm{U}) ; 100 \mu \mathrm{m}$ : (A, G, I, L, Q, T, W); $20 \mu \mathrm{m}(\mathrm{B}, \mathrm{C}, \mathrm{M}, \mathrm{S}, \mathrm{V}) ; 10 \mu \mathrm{m}(\mathrm{D}, \mathrm{E})$. 
A

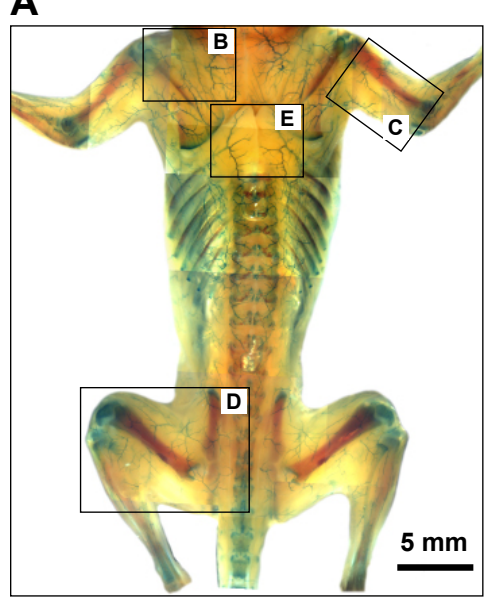

B
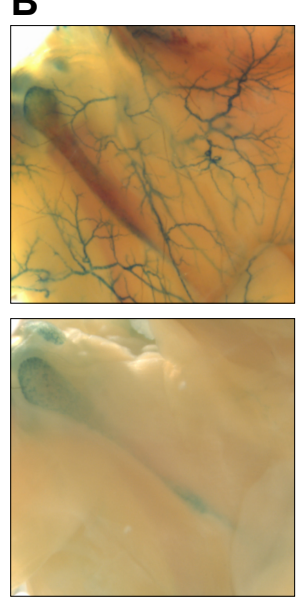

C
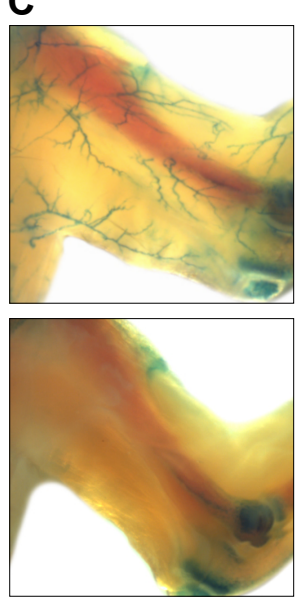

D
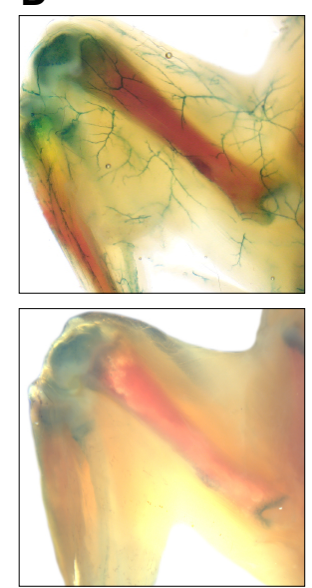

E
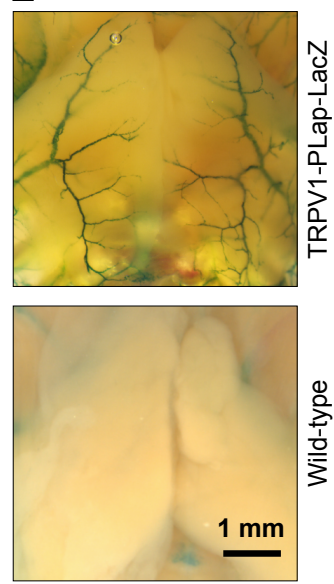

Figure 2. Arterial TRPV1 expression in a whole mouse preparation. (A-D), Whole-animal nLacZ staining in a 2 week old TRPV1 $1^{\text {PLAP-nlacZ }}$ mouse (skin removed) versus a control (wildtype) mouse shows extensive arterial TRPV1 expression in skeletal muscles and (E), interscapular brown adipose tissue. Note non-specific staining in bone tissues. 


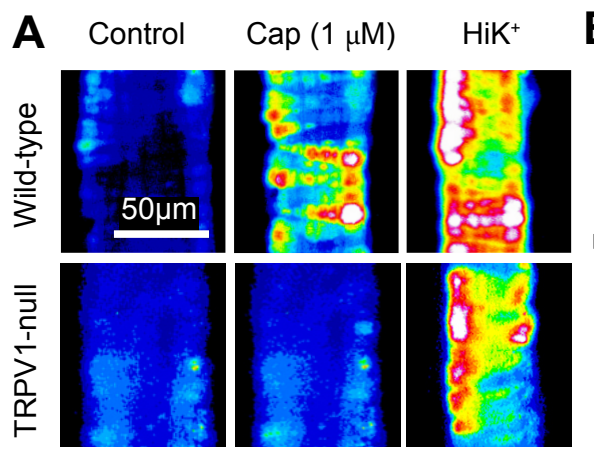

E

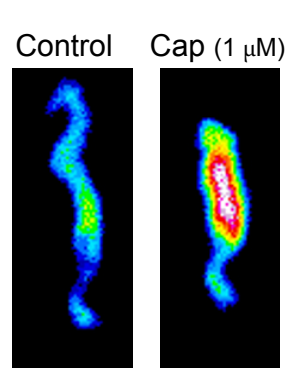

H

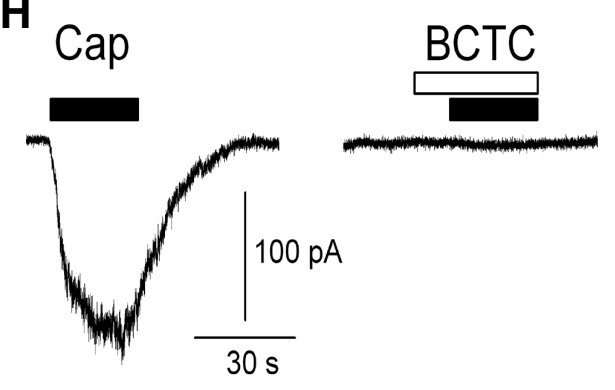

$-W T$

- TRPV1-null

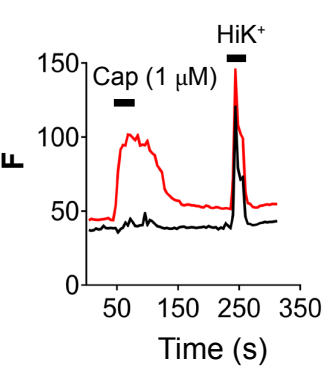

$\mathbf{F}-\mathrm{TRPV}^{+}{ }^{+}$cells

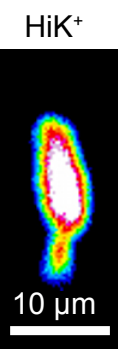

C

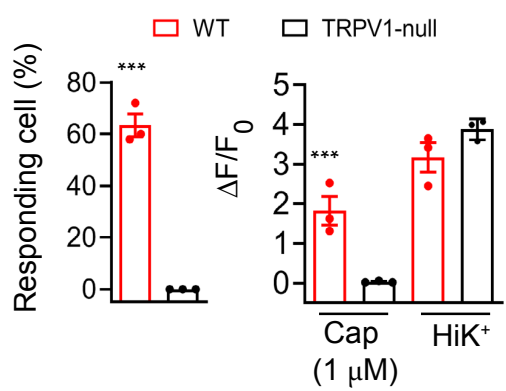

G $\square 0 \mathrm{mM} \mathrm{Ca}^{2+}$

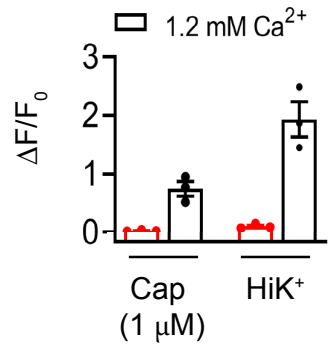

I $\square$ Cap $5 \mu \mathrm{M}$ ВСТС $5 \mu \mathrm{M}$

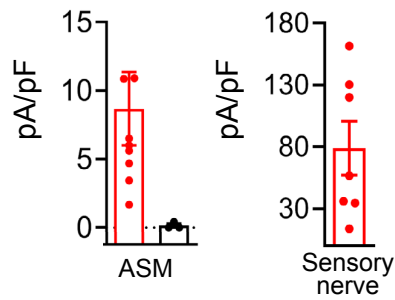

Figure 3. TRPV1 functionality in arterial smooth muscle cells. (A-D), Capsaicin $(1 \mu \mathrm{M})$ and $\mathrm{KCl}(50 \mathrm{mM})$ evoked $\mathrm{Ca}^{2+}$ signaling in isolated cerebellar arteries from wild type and TRPV1null mice $(\mathrm{n}=40-70$ cells in the groups from 3 independent experiments, $* * * P<0.001)$. ( $\mathbf{E}$ and F), Capsaicin-evoked $\mathrm{Ca}^{2+}$ signaling in dissociated ASM cells from TRPV1-Cre:tdTomato mice is restricted to TRPV1 ${ }^{+}$cells $\left(\mathrm{n}=20-25\right.$ cells per group). $(\mathbf{G})$, Capsaicin and $\mathrm{K}^{+}$evoked responses require extracellular $\mathrm{Ca}^{2+}(\mathrm{n}=20-30$ cells per group). (H), Representative current traces in a voltage-clamped ASM cell $(10 \mathrm{pF})$ in response to capsaicin (filled bars, $5 \mu \mathrm{M}$ ) with or without the TRPV1 antagonist BCTC (empty bars, $5 \mu \mathrm{M}$ ), and recovery after washout. (I), Mean current density in ASM cells for capsaicin $(n=9)$ and capsaicin + BCTC $(n=3)$, and in sensory nerves $(n=7)$. 
bioRxiv preprint doi: https://doi.org/10.1101/2020.02.04.934117; this version posted February 25, 2020. The copyright holder for this preprint (which was not certified by peer review) is the author/funder. All rights reserved. No reuse allowed without permission.

A Axillary Brachial Medial Subscapular of brachial Radial branch
lar of brachial

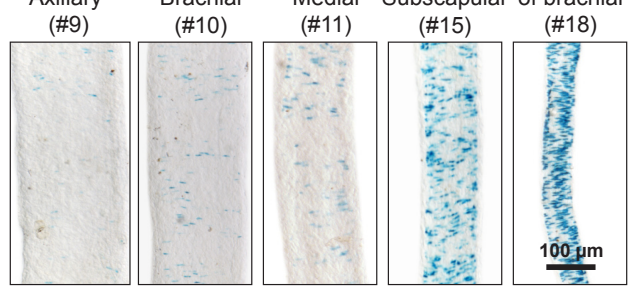

B

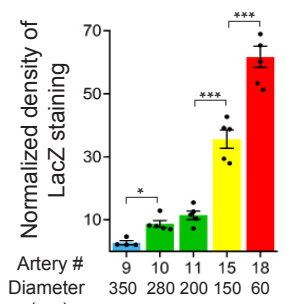

C

D

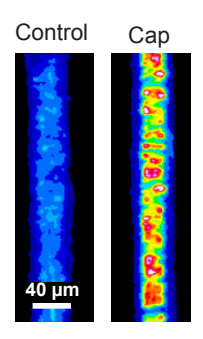

E

$(\mu \mathrm{m})$

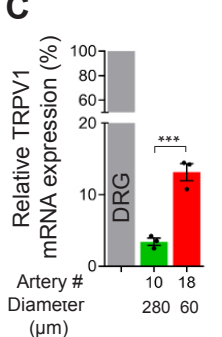

$\mathbf{F}$
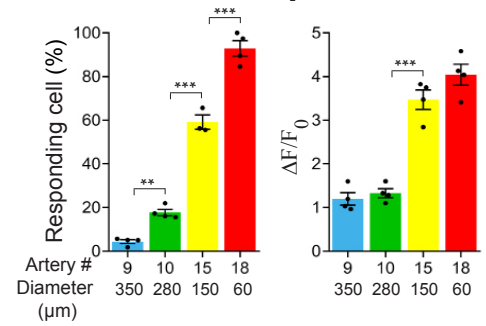

G

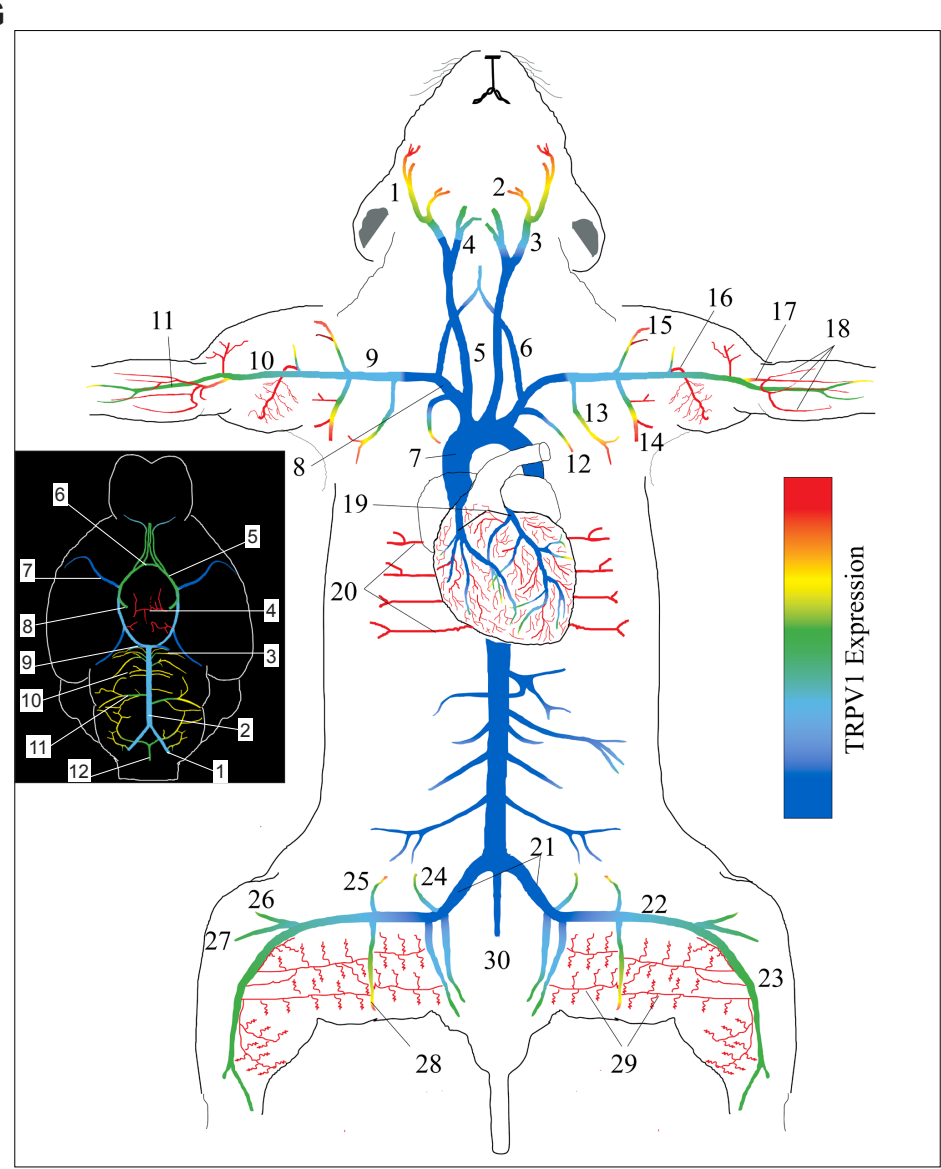

Figure 4. An arterial map of functional TRPV1 expression. (A and B), TRPV1 expression (nuclear LacZ staining) in forelimb arteries and muscle branches versus vessel diameter $(\mathrm{n}=4$ 6 arteries from 5 mice per group, $* P<0.05$, $* * * P<0.001)$. (C), TRPV1 mRNA measured by qRT-PCR in small and large-diameter arteries relative to DRG $(\mathrm{n}=3-4$ mice $),{ }^{* * *} P<0.001$. (D to F), Capsaicin $(1 \mu \mathrm{M})$ evoked $\mathrm{Ca}^{2+}$ responses in forelimb arteries of different diameter $(\mathrm{n} \geq$ 85 - 150 cells per group from 3 independent experiments, $* * P<0.01$, $* * * P<0.001)$. (G), Heatmap of TRPV1 expression in arteries based on TRPV1 $1^{\text {PLAP-nlacZ }}$ mice $(\mathrm{n} \geq 15$ mice) and confirmed by functional imaging. Inset shows the density of TRPV1 expression in cerebral arteries. Arterial color-coding is similarly applied to $\boldsymbol{B}$ to $\boldsymbol{F}$. Artery nomenclature is included in table S1. 
A

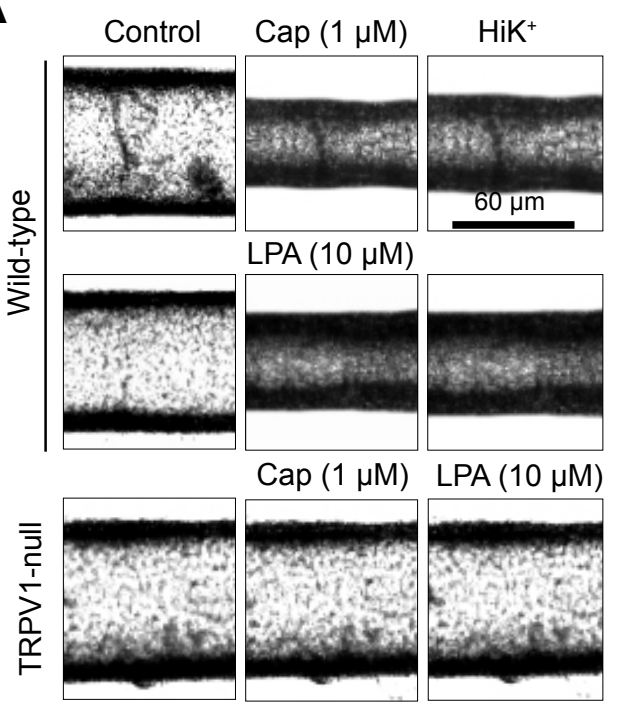

D

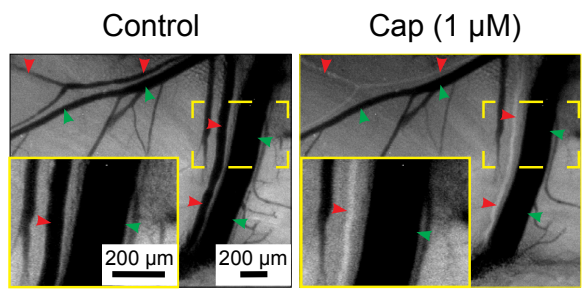

$\mathbf{F}$

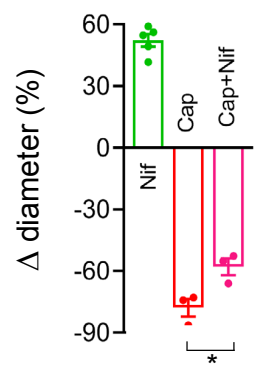

G
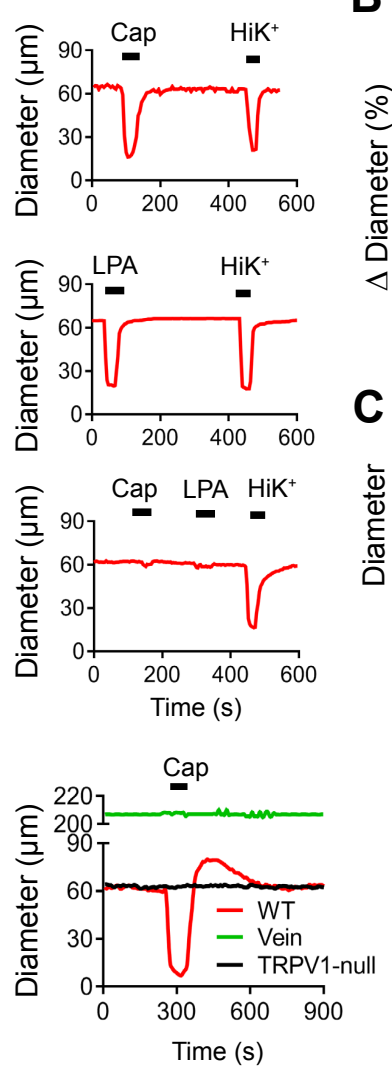

B
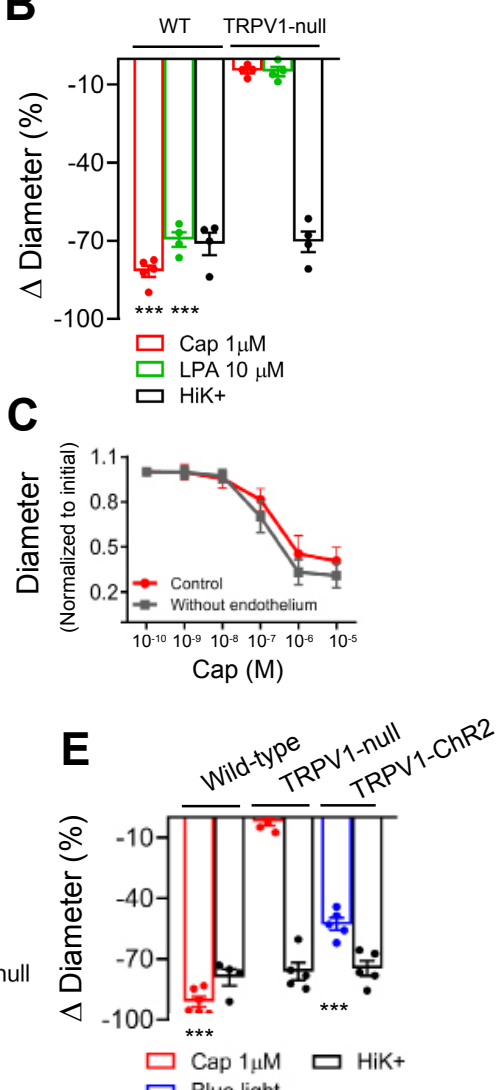

Figure 5. TRPV1 agonists constrict skeletal muscle arterioles. (A, B and C), Capsaicin (1 $\mu \mathrm{M})$ and LPA $(\mathrm{C} 18: 1,10 \mu \mathrm{M})$ constrict isolated, pressurized $(60 \mathrm{mmHg})$ arteries from wild-type but not TRPV1-null mice. (C), Capsaicin constricts intact and endothelium denuded gracilis arteries with similar potency $(n=6)$. ( $(\mathbf{D}$ and $\mathbf{E})$, Intravital imaging shows that capsaicin constricts radial branch arteries (red arrowheads) without affecting veins (green arrowheads). The inset (solid yellow) show expanded view of the designated area (broken yellow). Arteries from TRPV1-null mice are unresponsive to capsaicin and blue-light constricts arteries from TRPV1-Cre:ChR2 mice ( $\mathrm{n}=4$ - 7 arteries from 3 - 5 mice per group, $* * * P<0.001)$. (F), In vivo arteriole diameter following treatment with nifidepine $(3 \mu \mathrm{M})$, capsaicin, and nifedipine/capsaicin, $(\mathrm{n}=3-5$ arteries from 3 mice per group, $* P<0.05)$. (G), Proposed model of $\mathrm{Ca}^{2+}$-entry pathways underlying capsaicin/LPA induced vasoconstriction. 

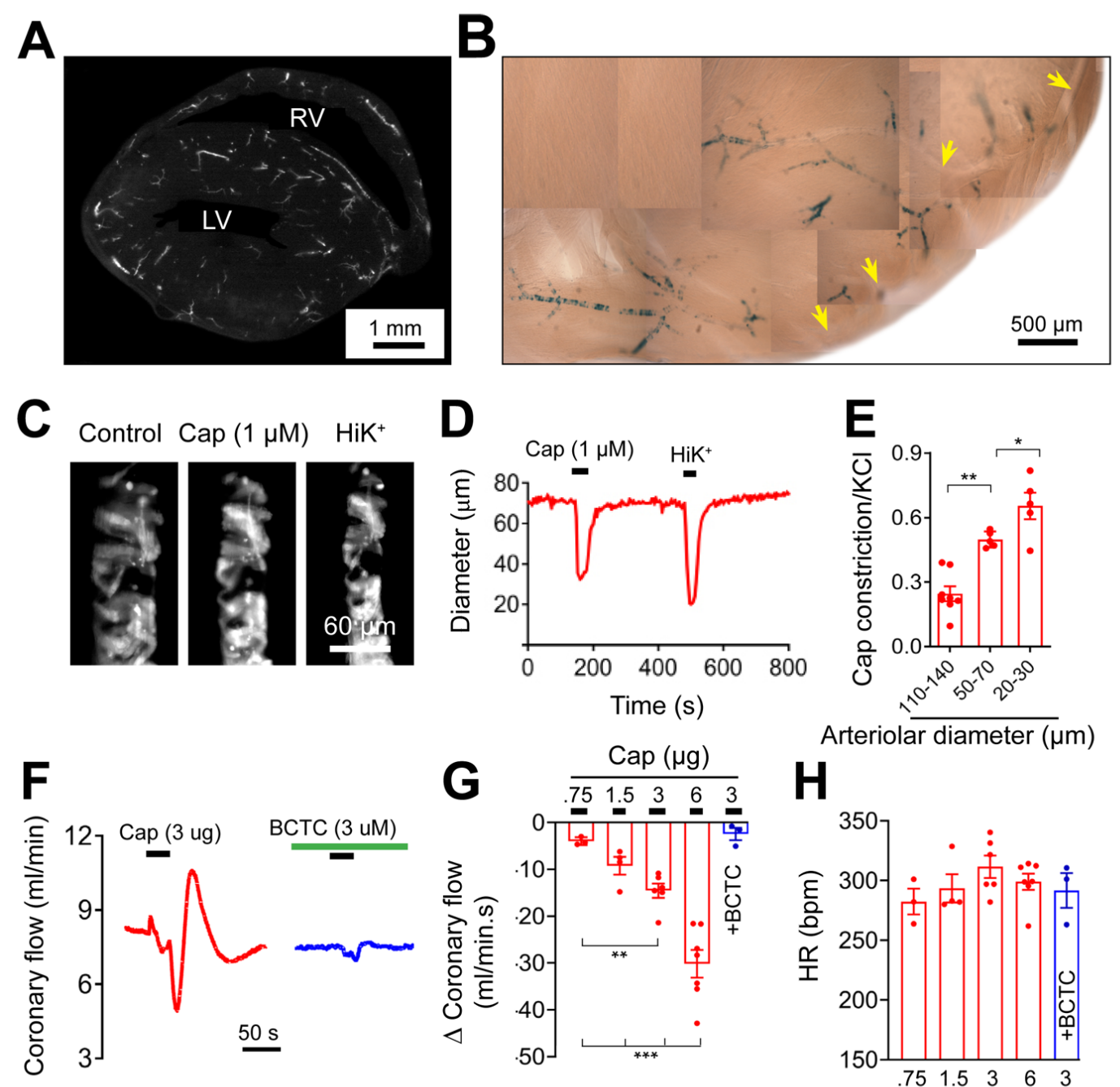

Arteriolar diameter $(\mu \mathrm{m})$

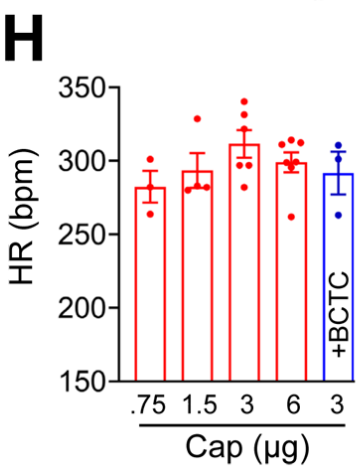

Figure 6. Capsaicin constricts coronary arterioles and reduces coronary perfusion. (A and B), Sagittal sections $(150 \mu \mathrm{m})$ of hearts from TRPV1-Cre:tdTomato and TRPV1-nLacZ mice reveal TRPV1 expression in small arteriole branches (yellow arrowheads denote the left coronary artery). (C-E) Capsaicin preferentially constricts small arterioles in situ in slice preparations from hearts of TRPV1-Cre:tdTomato mice. Data are normalized to $\mathrm{KCl}(40 \mathrm{mM})(\mathrm{n}$ $=5)$. (F-H), Capsaicin dose-dependently decreases coronary perfusion in isolated rat hearts without affecting the heart rate. BCTC abolishes the effect of capsaicin $(\mathrm{n}=3-7, * P<0.05$, $* * P<0.01$, *** $P<0.001)$. 

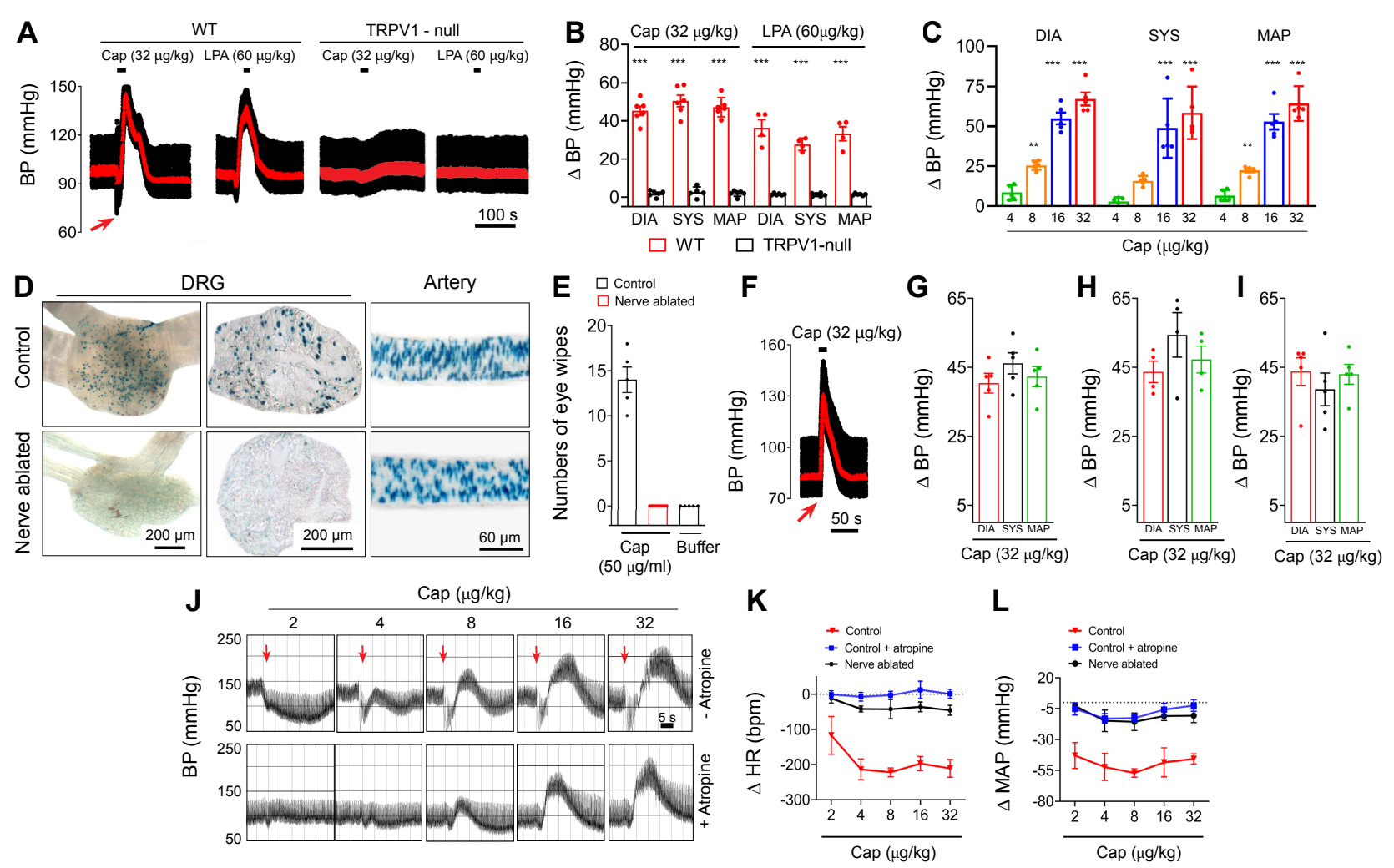

$\mathbf{L}$

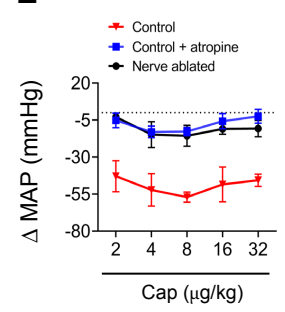

Figure 7. TRPV1 regulates systemic blood pressure. (A and B), Blood pressure (BP) changes in wild-type and TRPV1-null mice in response to intravenous (IV) infusion (20 s) of capsaicin or LPA $(\mathrm{C} 18: 1)(\mathrm{n}=4-7, * * * P<0.001)$. Mean arterial pressure is shown in red. $(\mathbf{C})$, Mean changes in systolic BP, diastolic BP and MAP in rats during bolus IV capsaicin $(\mathrm{n}=6, * * P<$ 0.01 , ***P<0.001). (D), nuclear LacZ staining in L5 dorsal root ganglion (section and whole ganglion) and arteries from mice with or without neonatal RTX treatment. (E), Mean eye-wipes in response to capsaicin in nerve-ablated rats $(n=5)$. $(\mathbf{F}$ and $\mathbf{G})$, BP responses to IV capsaicin in sensory nerve ablated mice $(n=4)$ and $(\mathbf{H})$, rats $(n=5)$. $(\mathbf{I})$, Change in BP in conscious mice in response to IV administration (20 s) of capsaicin $(n=4)$. $(\mathbf{J})$, BP recordings in a rat in response to escalating bolus IV doses of capsaicin with or without atropine pretreatment [Note: atropine abolishes the rapid decrease in BP reflecting a Bezold-Jarisch reflex]. (K and $\mathbf{L}$ ), Mean changes in heart rate and MAP measured immediately after bolus IV capsaicin in rats $(n=6)$. 

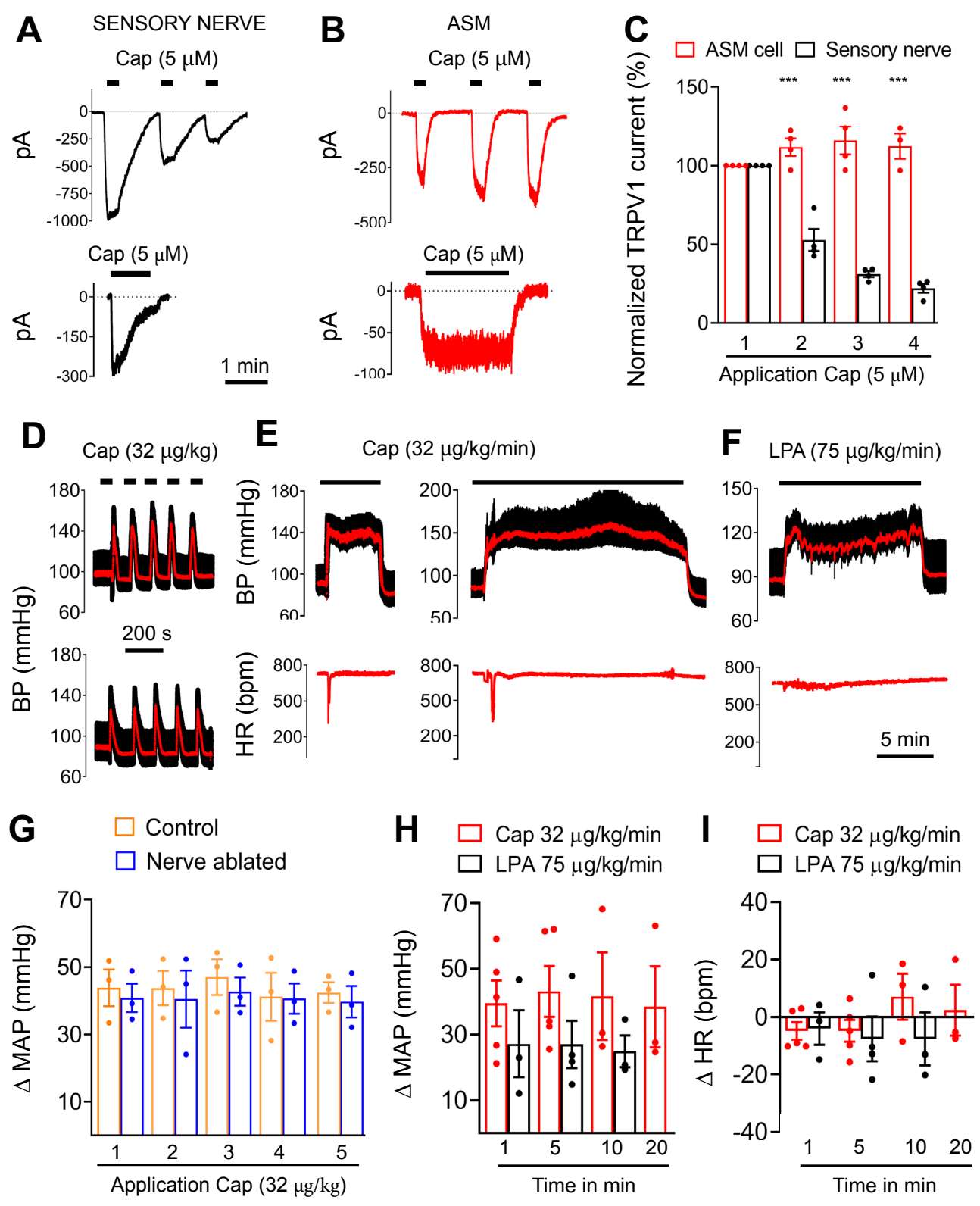

Figure 8. TRPV1 mediates persistent vasoconstriction. (A and B), Representative current traces in sensory neurons and ASM cells in response to repetitive or sustained application of capsaicin. (C), Mean normalized peak current evoked by repeated capsaicin treatment $(\mathrm{n}=4)$, $* * * P<0.01$ (neurons versus ASM cell). (D-F), Representative BP traces in response to bolus or continuous infusion of capsaicin or LPA. (G-I), Mean changes in BP and heart rate (HR) in response to repeated or continuous capsaicin/LPA administration, $\mathrm{n}=3-5$. 